\title{
O gênero Bacillus aplicado ao controle biológico de doenças de plantas
}

\author{
The Bacillus genus applied to the biological control of plant diseases \\ El género Bacillus aplicado al control biológico de enfermedades vegetales
}

Recebido: 02/07/2021 | Revisado: 09/07/2021 | Aceito: 13/07/2021 | Publicado: 24/07/2021

\author{
Thiago Anchieta de Melo \\ ORCID: https://orcid.org/0000-0003-0796-6388 \\ Universidade Estadual do Maranhão, Brasil \\ E-mail: thiagodemelo.uema@gmail.com \\ Ingrid Tayane Vieira da Silva do Nascimento \\ ORCID: https://orcid.org/0000-0003-2858-4549 \\ Universidade Estadual do Maranhão, Brasil \\ E-mail: tayanevsn@hotmail.com \\ Ilka Márcia Ribeiro de Souza Serra \\ ORCID: https://orcid.org/0000-0003-1622-5434 \\ Universidade Estadual do Maranhão, Brasil \\ E-mail: ilka.tt@hotmail.com
}

\begin{abstract}
Resumo
Para atender à crescente demanda mundial por alimentos livres de resíduos químicos, muitos microrganismos vêm sendo utilizados como agentes de biocontrole de importantes fitopatógenos e pragas em culturas importantes comercialmente. O gênero Bacillus é amplamente utilizado para este fim, assim, objetivou-se neste artigo concentrar as principais atualizações sobre o gênero, levando em consideração aspectos biológicos, taxonômicos, genéticos e as aplicabilidades e potencialidades desse grupo de procariotos em ações de manejo biológico de outros organismos. As pesquisas demonstram grande versatilidade do gênero Bacillus com a capacidade de ocupar diferentes nichos, dentre eles: solo, forragem, água e alimentos; além de possuir muitas características que definem um bom agente de controle biológico, sendo também, amplamente aplicadas no manejo de fitonematoides. Com os avanços tecnológicos, por meio de estudos de biologia molecular, ficou evidente a possibilidade de uso do gênero Bacillus no manejo biológico, sendo, portanto, foco de importantes pesquisas científicas.
\end{abstract}

Palavras-chave: Biocontrole; Bactéria; Fitopatologia; Manejo biológico.

\begin{abstract}
To meet the growing world demand for food free of chemical residues, many microorganisms have been used as biocontrol agents for important phytopathogens and pests in important commercial crops. The genus Bacillus is widely used for this purpose, so the objective of this article was to concentrate the main updates on the genus, considering biological, taxonomic, genetic aspects and the applicability and potential of this group of prokaryotes in biological management actions of other organisms. The research demonstrates great versatility of the Bacillus genus with the capacity to occupy different niches, among them: soil, forage, water, and food; in addition to having many characteristics that define a good biological control agent, they are also widely applied in the management of phytomatomatoids. With technological advances, through studies of molecular biology, it became evident the possibility of using the genus Bacillus in biological management, thus being the focus of important scientific research. Keywords: Biocontrol; Bacterium; Phytopathology; Biological management.
\end{abstract}

\section{Resumen}

Para satisfacer la creciente demanda mundial de alimentos libres de residuos químicos, se han utilizado muchos microorganismos como agentes de control biológico de importantes fitopatógenos y plagas en importantes cultivos comerciales. El género Bacillus es ampliamente utilizado para este fin, por lo que el objetivo de este artículo fue concentrar las principales actualizaciones sobre el género, teniendo en cuenta los aspectos biológicos, taxonómicos, genéticos y la aplicabilidad y potencialidad de este grupo de procariotas en acciones de manejo biológico de otros organismos. Las investigaciones demuestran una gran versatilidad del género Bacillus con la capacidad de ocupar diferentes nichos, entre ellos: suelo, forraje, agua y alimento; además de tener muchas características que definen un buen agente de control biológico, también se aplican ampliamente en el manejo de fitomatoides. Con los avances tecnológicos, a través de estudios de biología molecular, se hizo evidente la posibilidad de utilizar el género Bacillus en el manejo biológico, siendo así el foco de importantes investigaciones científicas.

Palabras clave: Biocontrol; Bacteria; Fitopatologia; Manejo biológico. 


\section{Introdução}

As interações entre microrganismos compartilhando um mesmo nicho ecológico revestem-se de características fundamentalmente competitivas. As práticas de controle biológico que visam a proteção direta das plantas envolvem a utilização de um microrganismo antagonista no sítio de infecção antes ou após a ocorrência do processo infectivo (Romeiro, 2007). Os mecanismos utilizados pelos organismos biocontroladores são: (a) o enfraquecimento ou a eliminação dos patógenos de plantas, por meio de um antagonismo direto; (b) a produção de antibióticos (toxinas) que agem sobre os patógenos; (c) a alta habilidade competitiva por espaço e nutriente para a sobrevivência quando na presença de um outro microrganismo; (d) a produção de enzimas que degradam os componentes celulares dos patógenos; (e) a indução dos mecanismos de respostas de defesa em plantas, em um processo conhecido como indução de resistência e, possivelmente, outros (Tuzun, 2001).

Embora muitos microrganismos se mostrem eficientes agentes de biocontrole de importantes fitopatógenos e pragas em culturas importantes comercialmente, em condições de laboratório, casa-de-vegetação e até mesmo, no campo, poucas cepas desses microrganismos são realmente registradas, liberadas para o uso e disponíveis comercialmente. Mesmo com esse entrave, é esperado que a utilização do controle biológico encontre cada vez mais espaço entre os produtores e que essa medida de manejo seja uma prática corriqueira entre os sistemas de produção agrícola que caminham para atender à crescente demanda mundial por alimentos livres de resíduos químicos, produzidos de forma a preservar o equilíbrio do agroecossistema, a saúde do homem e dos animais. Uma vez que essas cepas podem apresentar variações genéticas dos mais diversos tipos, uma categorização e correto entendimento desses organismos se faz necessário, a exemplo das bactérias do gênero Bacillus. Tais organismos já foram encontrados e descritos em diferentes nichos, sendo ampla a sua utilização e aplicabilidade para fins de controle biológico.

Nesse sentido, este artigo tem por objetivo concentrar as principais atualizações sobre gênero, levando em consideração aspectos biológicos, taxonômicos, genéticos e as aplicabilidades e potencialidades desse grupo de procariotos em ações de manejo biológico de outros organismos.

\section{Metodologia}

Este trabalho de pesquisa fundamental, de perfil exploratório e de natureza qualitativa, pô-se a descrever sobre o tema a partir de opiniões, impressões e pontos de vistas obtidos a partir dos instrumentos de coleta de dados, o que trouxe informações acerca dos fatores impulsionadores observados no campo de estudo investigado (Estrela, 2018).

O trabalho foi desenvolvido por método de levantamento de dados (artigos) para a construção de uma revisão de literatura. Os critérios de análises seguiram os parâmetros de inclusão e exclusão, conforme descritos a seguir:

Critérios de inclusão: artigos completos em inglês e/ou português, indexados nas plataformas de pesquisa Scielo, Portal de Periódicos da CAPES, Web of Science, Science Directe Google Scholar, publicados sobre a temática, independente do período ou época de publicação; trabalhos cujo as palavras-chaves constantes no título ou nos termos de indexação fossem: Biocontrole; bactéria; fitopatologia; manejo biológico; Bacillus.

Critérios de exclusão: trabalhos incompletos ou não disponibilizados na íntegra (open access negado); pesquisas sem embasamento teórico coerente com a área, apresentando com metodologia difusa ou sem clareza; trabalhos não indexados.

\section{Resultados e Discussão}

\subsection{Definições}

Os termos 'controle biológico' e sua abreviação 'biocontrole', têm sido utilizados em diferentes áreas da biologia, especialmente, na entomologia e fitopatologia. Na entomologia, o termo é aplicado para descrever a utilização de insetos 
predadores, nematoides entomopatogênicos ou agentes microbianos utilizados para diminuir populações de diferentes pragas (Pal \& Gardener, 2006). Em fitopatologia, os termos são utilizados para designar microrganismos antagonistas que controlam doenças em plantas, bem como aqueles microrganismos patogênicos que são aplicados no controle de populações de plantas daninhas. Nas duas áreas, o organismo que suprime ou controla pragas ou patógenos, respectivamente, é designado como agente de controle biológico.

De maneira mais abrangente, o termo 'controle biológico' é utilizado para se referir a utilização de produtos naturais extraídos ou fermentados a partir de várias fontes biológicas. Essas formulações podem ser misturas simples de ingredientes naturais com atividades específicas ou, complexas misturas com efeitos múltiplos no hospedeiro e na praga ou patógeno alvo. Sendo que essas misturas têm a capacidade de minimizar a atividade de organismos vivos, estas são referidas como 'biopesticidas' ou ainda, 'biofertilizantes', dependendo do benefício primário promovido sobre a planta hospedeira.

As várias definições encontradas na literatura especializada sobre o tema podem ser controversas. Por exemplo, o United States National Research Council, leva em consideração todo o desenvolvimento biotecnológico das últimas décadas e se refere ao controle biológico como "a utilização de organismos naturais ou modificados, genes ou produtos de genes que reduzem os efeitos de organismos indesejáveis, favorecendo cultivos de importância agrícola, insetos benéficos e microrganismos”. Entretanto, essa definição gera uma série de debates entre os pesquisadores da área que, frequentemente, a consideram ampla demais (US Congresss, 1995).

As definições de biocontrole diferem quanto ao alvo a ser controlado, número, tipo e fonte do agente biológico e também quanto ao grau e momento de intervenção humana. De modo mais abrangente, o controle biológico trata da supressão de uma atividade danosa, gerada por um organismo, por outro ou outros organismos, frequentemente denominados 'inimigos naturais'. As plantas, geralmente, respondem à aplicação de agentes de controle biológico, patogênicos ou não, com a ativação dos seus mecanismos de defesa. Essa indução da resistência do hospedeiro pode ser considerada uma forma de controle biológico. Assim, de forma mais precisa, o controle biológico se refere à utilização intencional de organismos vivos, residentes ou não do local de ação, para suprimir as atividades e populações de um ou mais fitopatógenos. Isso pode envolver a utilização de inoculantes microbianos que suprimem um único tipo ou classe de doença em plantas ou ainda, pode envolver o manejo do solo para a promoção da atividade combinada de microrganismos nativos com plantas, o que contribui para a supressão geral de doenças.

Vários microrganismos são utilizados na perspectiva do controle biológico e dentre as espécies microbianas com esse potencial, encontramos fungos e bactérias. Com relação aos agentes bacterianos biocontroladores, merecem destaque diferentes espécies do gênero Bacillus por serem as mais utilizadas. Aspectos gerais sobre a biologia, morfologia, fisiologia e genética das principais espécies do gênero, bem como seus usos e aplicações serão melhor exploradas a seguir.

\subsection{O gênero Bacillus}

Uma das primeiras bactérias a ser descrita na literatura foi a espécie Vibrio subtilis por Ehrenberg em 1835. Em 1872, Corn renomeou o organismo, denominando-o Bacillus subtilis (Gordon, 1981). A partir daí, tal organismo passou a ser considerado a espécie-tipo de um gênero amplo e extremamente diverso, fazendo parte da família Bacillaceae (Slepecky \& Hemphill, 2006). A principal característica dessa família é a produção de endósporos circulares, ovalados (elipsoides) ou cilíndricos, estruturas com alto índice de refração quando expostas à luz, formadas no interior da célula bacteriana. Os endósporos foram inicialmente descritos por Cohn na espécie B. subtilis, sendo após, descritos novamente por Koch na espécie B. anthracis (única espécie de importância para vertebrados no gênero). Cohn demonstrou a resistência dos endósporos ao calor, enquanto Koch foi o primeiro a descrever o ciclo de formação do endósporo em uma célula bacteriana e a formação de uma nova célula a partir do endósporo formado (Keynan \& Sandler, 1983). Por conta da descoberta da resistência não usual do 
endósporo, somada às demonstrações de Koch e a importância da espécie B. anthracis, o gênero despertou o interesse de pesquisadores e se configurou como uma das espécies bacterianas mais estudadas, inclusive nos dias de hoje (Figura 1).

Figura 1. Micrografia obtida por contraste de fases da bactéria Bacillus megaterium formando endósporos (estruturas em refração no interior das células).
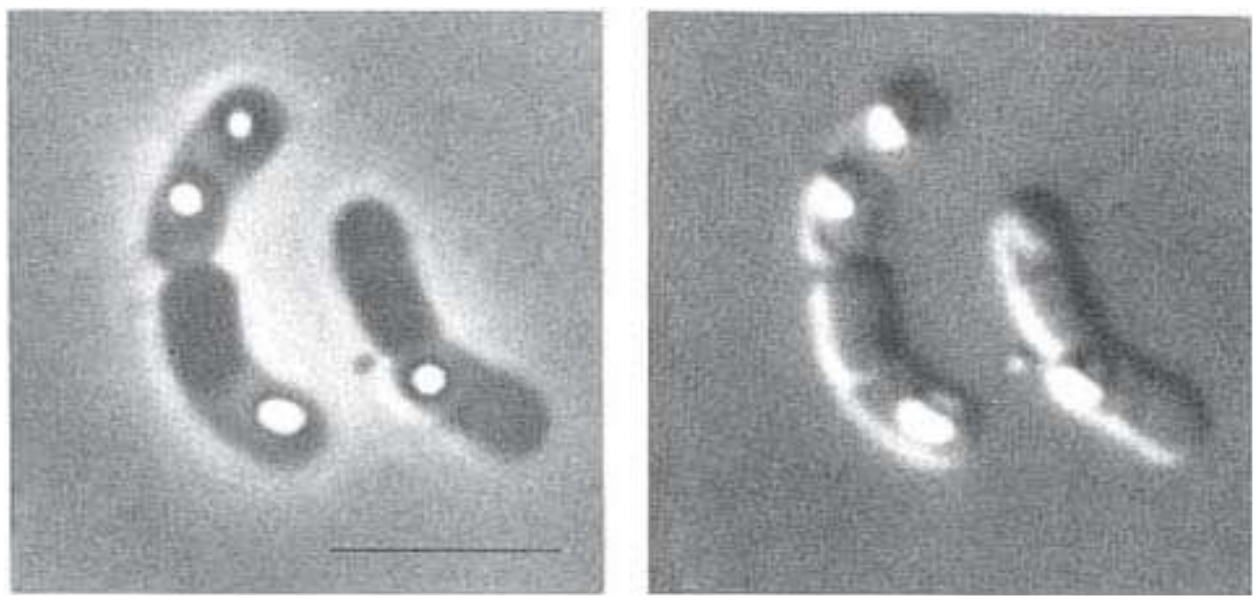

Fonte: Extraído de Kleynan e Sandler (1983). Barra: 5 um.

Bactérias do gênero Bacillus já foram isoladas de diferentes habitats e aquelas que apresentam maior importância econômica ou ecológica estão disponíveis na Tabela 1. O aquecimento do inóculo, quando cultivado em diferentes temperaturas, concentrações de íon hidrogênio, graus de aeração e substratos, resultou no isolamento de diferentes espécies formadoras de endósporos. Os principais meios de cultivo utilizados para o isolamento das diferentes espécies de Bacillus estão listados na Tabela 2.

Desde a descrição, a habilidade de produzir endósporos tem sido utilizada como a primeira característica para a diferenciação do gênero. A família Bacillaceae foi primeiramente organizada por Fisher em 1895 (Gordon, 1981). As características das espécies que constituem o gênero Bacillus que as distinguem dos demais membros dessa família (todos formadores de endósporos), são a sua natureza aeróbica estrita ou facultativa, o formato baciliforme e a produção de catalase. Os outros gêneros que compõe a família incluem os Sporolactobacillus, que são microaerofílicos e não produzem catalase, os Clostridium, anaeróbicos e não redutores do íon sulfato, as Sporosarcinas, que têm formato de $\operatorname{cocos} \mathrm{e}$ os Thermoactinomycetes, que são bactérias filamentosas, portanto, de morfologia completamente diferente do gênero Bacillus. 
Tabela 1. Habitats mais comuns das diferentes espécies do gênero Bacillus.

\begin{tabular}{|c|c|}
\hline Nome da espécie & Habitats dos quais foram isoladas \\
\hline B. subtilis & Solo, água \\
\hline B. acidocaldarius & Água termal ácida e solo \\
\hline B. alcadolophilus & Solos enriquecidos e altamente alcalinos ( $\mathrm{pH} 10)$ \\
\hline B. alvei & Solo, larvas parasitas de abelhas \\
\hline B. amylolyticus & Solo \\
\hline B. anthracis & Animais parasitados pela bactéria \\
\hline B. azotoformans & Solo \\
\hline B. badius & Fezes, solo, fontes marinhas \\
\hline B. cereus & Solo, alimentos \\
\hline B. circulans & Solo \\
\hline B. coagulans & Alimentos ácidos \\
\hline B. fastidiosus & Solo, cama de frango \\
\hline B. firmus & Solo, regiões salinas \\
\hline B. globisporus & Solo, água \\
\hline B. insolitus & Solo \\
\hline B. larvae & Larvas parasitas de abelhas \\
\hline B. laterosporus & Solo, água \\
\hline B. lautus & Solo, fezes \\
\hline B. lentimorbus & Larvas encontradas em mel produzido por abelhas \\
\hline B. lentus & Solo, alimentos \\
\hline B. licheniformes & Solo \\
\hline B. macerans & Plantas, alimentos \\
\hline B. macquariensis & Solo subantártico \\
\hline B. marinus & Sedimento marinho \\
\hline B. megaterium & Solo \\
\hline B. mycoides & Solo \\
\hline B. pabuli & Solo, forragem \\
\hline B. pantothenicus & Solo \\
\hline B. pasteurii & Solo, água, esgoto \\
\hline B. popilliae & Patogênica a besouros \\
\hline B. psychrophilus & Solo, água \\
\hline B. pumilus & Solo \\
\hline B. schlegelii & Sedimentos encontrados em lagos \\
\hline B. sphaericus & Solo, sedimentos aquáticos, alimentos \\
\hline B. stearotermophilus & Solo, alimentos \\
\hline B. thermoglucosidasius & Solo \\
\hline B. thurigiensis & Solo, alimentos \\
\hline B. validus & Solo \\
\hline
\end{tabular}


Tabela 2. Principais meios de cultivo estabelecidos e utilizados para o isolamento de diferentes espécies do gênero Bacillus.

\begin{tabular}{|c|c|}
\hline Espécie & Meio de cultivo \\
\hline B. acidocaldarius & $\begin{array}{l}\text { Parte A: }\left(\mathrm{NH}_{4}\right)_{2} \mathrm{SO}_{4}, 0,4 \mathrm{~g} ; \mathrm{MgSO}_{4}, 1,0 \mathrm{~g} ; \mathrm{CaCl}_{2} 2 \mathrm{H}_{2} \mathrm{O}, 0,5 \mathrm{~g} ; \mathrm{KH}_{2} \mathrm{PO}_{4}, 6,0 \mathrm{~g} ; 1 \\
\mathrm{~L} \text { de água destilada; } \mathrm{pH} \text { ajustado para } 4,0 \\
\text { Parte B: dextrose, } 2,0 \mathrm{~g} \text {; extrato de levedura, } 2,0 \mathrm{~g} ; 1 \mathrm{~L} \text { de água destilada } \\
\text { Junção da parte A com a parte B depois da esterilização }\end{array}$ \\
\hline B. alcalophilus & $\begin{array}{l}\text { Parte A: dextrose, } 1,0 \mathrm{~g} \text {; peptona, } 5,0 \mathrm{~g} \text {; extrato de levedura, } 5,0 \mathrm{~g} ; \mathrm{KH}_{2} \mathrm{PO}_{4} \text {, } \\
10,0 \mathrm{~g} ; \mathrm{MgSO}_{4} 7 \mathrm{H}_{2} \mathrm{O}, 0,2 \mathrm{~g} ; 900 \mathrm{~mL} \text { de água destilada } \\
\text { Parte } \mathrm{B}: \mathrm{Na}_{2} \mathrm{CO}_{3} 10 \mathrm{H}_{2} \mathrm{O}, 20,0 \mathrm{~g} ; 100 \mathrm{~mL} \text { de água destilada } \\
\text { Junção da parte A com a parte B depois da esterilização (pH final: 10,5) }\end{array}$ \\
\hline B. brevis & $\begin{array}{l}\mathrm{K}_{2} \mathrm{HPO}_{4}, 0,2 \mathrm{~g} ; \mathrm{MgSO}_{4} 7 \mathrm{H}_{2} \mathrm{O}, 0,02 \mathrm{~g} ; \mathrm{NaCl}, 0,02 \mathrm{~g} ; \mathrm{FeSO}_{4} 7 \mathrm{H}_{2} \mathrm{O}, 0,01 \mathrm{~g} ; \\
\mathrm{MnSO}_{4} \mathrm{H}_{2} \mathrm{O}, 0,01 \mathrm{~g} \text {; betaína } \mathrm{HCl} \text { ou valina, } 0,05 \mathrm{M} \text {; ágar, } 16,0 \mathrm{~g} ; 1 \mathrm{~L} \text { de água } \\
\text { destilada }\end{array}$ \\
\hline B. fastidiosus & $\begin{array}{l}\mathrm{K}_{2} \mathrm{HPO}_{4}, 0,8 \mathrm{~g} ; \mathrm{KH}_{2} \mathrm{PO}_{4}, 0,2 \mathrm{~g} ; \mathrm{MgSO}_{4} 7 \mathrm{H}_{2} \mathrm{O}, 0,05 \mathrm{~g} ; \mathrm{CaCl}_{2} 2 \mathrm{H}_{2} \mathrm{O}, 0,05 \mathrm{~g} ; \\
\mathrm{FeSO}_{4} 7 \mathrm{H}_{2} \mathrm{O}, 0,015 \mathrm{~g} ; \mathrm{MnSO}_{4} \mathrm{H}_{2} \mathrm{O}, 0,01 \mathrm{~g} ; \text { ácido úrico, } 10,0 \mathrm{~g} ; 1 \mathrm{~L} \text { de água } \\
\text { destilada }\end{array}$ \\
\hline B. lentus & $\begin{array}{l}\text { Peptona, } 10,0 \mathrm{~g} \text {; extrato de carne, } 10,0 \mathrm{~g} \text {; ágar, } 15,0 \mathrm{~g} \text {; adicionar } 1 \mathrm{~L} \text { de água } \\
\text { destilada e ajustar o pH para 7,0-7,5; após esterilização, adicionar } 100 \mathrm{~g} \text { de } \\
\text { ureia e aquecer por } 10 \mathrm{~min}\end{array}$ \\
\hline B. licheniformis & $\begin{array}{l}\text { Peptona, 5,0 g; extrato de carne, } 3,0 \mathrm{~g} ; \mathrm{KNO}_{3}, 80,0 \mathrm{~g} ; 1 \mathrm{~L} \text { de água destilada; } \\
\text { ajustar o pH para 7,0; para criar condições anaeróbicas, fechar o frasco com } \\
\text { um tampão do tipo rolha }\end{array}$ \\
\hline B. marinus & $\begin{array}{l}\text { Peptona, } 5,0 \mathrm{~g} \text {; extrato de levedura, } 1,0 \mathrm{~g} ; \mathrm{FePO}_{4} 4 \mathrm{H}_{2} \mathrm{O}, 0,01 \mathrm{~g} \text {; ágar, } 15,0 \mathrm{~g} \text {; } \\
\text { água do mar envelhecida (guardada), } 750 \mathrm{ml} ; 250 \mathrm{~mL} \text { de água destilada; ajustar } \\
\text { o pH para } 7.6\end{array}$ \\
\hline B. pantothenicus* & Meio nutriente mais $4 \%(\mathrm{~m} / \mathrm{v}) \mathrm{NaCl}$ \\
\hline B. pasteurii* & Meio nutriente mais $2 \%(\mathrm{~m} / \mathrm{v})$ ureia \\
\hline B. schlegelii & $\begin{array}{l}\mathrm{Na}_{2} \mathrm{HPO}_{4} 2 \mathrm{H}_{2} \mathrm{O}, 4,5 \mathrm{~g} ; \mathrm{KH}_{2} \mathrm{PO}_{4}, 1,5 \mathrm{~g} ; \mathrm{NH}_{4} \mathrm{Cl}, 1,0 \mathrm{~g} ; \mathrm{MgSO}_{4} 7 \mathrm{H}_{2} \mathrm{O}, 0,2 \mathrm{~g} ; \\
\mathrm{CaCl}_{2} 2 \mathrm{H}_{2} \mathrm{O}, 0,01 \mathrm{~g} \text {; citrato férrico de amônia, 0,005 g; } \mathrm{NaHCO}_{3}, 0,5 \mathrm{~g} ; 5 \mathrm{~mL} \\
\text { de uma solução de microelementos }\left(\mathrm{ZnSO}_{4} 7 \mathrm{H}_{2} \mathrm{O}, 0,1 \mathrm{~g} ; \mathrm{MnCl}_{2} 4 \mathrm{H}_{2} \mathrm{O}, 0,03 \mathrm{~g} \text {; }\right. \\
\mathrm{H}_{3} \mathrm{BO}_{3}, 0,3 \mathrm{~g} ; \mathrm{CoCl}_{2} 6 \mathrm{H}_{2} \mathrm{O}, 0,02 \mathrm{~g} ; \mathrm{CuCl}_{2} 2 \mathrm{H}_{2} \mathrm{O}, 0,001 \mathrm{~g} ; \mathrm{NiCl}_{2} 6 \mathrm{H}_{2} \mathrm{O}, 0,02 \mathrm{~g} ; \\
\mathrm{Na}_{2} \mathrm{MoO}_{4} \cdot 2 \mathrm{H}_{2} \mathrm{O}, 0,03 \mathrm{~g} ; 1 \mathrm{~L} \text { de água destilada) Preparar a } 65{ }^{\circ} \mathrm{C}, 0,05 \mathrm{~atm} \mathrm{O} \mathrm{O}_{2} \\
+0,01 \mathrm{~atm} \mathrm{CO}_{2}+0,45 \mathrm{~atm} \mathrm{H} \mathrm{H}_{2}\end{array}$ \\
\hline B. stearothermophilus* & Meio nutriente ágar; incubação das culturas a $55^{\circ} \mathrm{C}$ \\
\hline
\end{tabular}

*A maioria das espécies de Bacillus crescem bem em meio nutriente e meio nutriente ágar.

Fonte: Baseado em Claus e Berkeley (1986).

\subsubsection{Características taxonômicas gerais das diferentes espécies do gênero Bacillus}

Os primeiros 107 anos de estudo com Bacillus spp. e todas as principais descobertas ao longo desse período, estão relacionadas a R. E. Gordon (1981) que, juntamente com seus colaboradores, conseguiram informações significativas que foram o alicerce para a atual classificação das espécies no gênero (Claus \& Berkeley, 1986; Gordon et al., 1973; Smith et al., 1946; 1952). Em um primeiro momento, a classificação desse grupo de bactérias era feita com base em apenas duas características: (i) crescimento aeróbico e (ii) formação de endósporo. O resultado disso foi o agrupamento de espécies bacterianas que apresentavam diferentes perfis fisiológicos e que ocupavam diferentes habitats. Essa heterogeneidade fisiológica, ecológica e, consequentemente, genética, dificultou a categorização do gênero e também, possíveis generalizações deste.

A gama de características fisiológicas do gênero é expressiva, tendo em vista que dentre as espécies, existem bactérias degradam a maioria dos substratos derivados tanto de plantas quanto de animais, isso inclui a celulose, amido, proteínas, ágar, hidrocarbonetos e outros. Ainda encontramos espécies produtoras de antibióticos, heterotróficas nitrificantes, desnitrificantes, fixadoras de nitrogênio, precipitadoras de íons de ferro, capazes de oxidar o selênio, espécies oxidantes e redutoras do manganês, quimiolitotróficas facultativas, alcalófilas, psicrófilas, termófilas e outras (Claus \& Berkeley, 1986; Norris et al., 1981; Slepecky, 1972). Assim, por conta dessa alta diversidade encontrada entre as espécies do gênero, a classificação desses 
indivíduos baseada apenas na biologia da formação de esporos, geralmente, leva a equívocos (Norris et al., 1981; Slepecky, 1972; Slepecky \& Leadbetter, 1977, 1984). Entretanto, sem dúvida nenhuma, a capacidade de produção de esporos, apresentada pelas espécies do gênero, possibilitou que estas alcançassem os mais diversos habitats nos quais hoje elas são encontradas (Tabela 1).

Atualmente, o gênero é composto por 145 espécies (Gordon, 1981). O entendimento dessas espécies cresceu de maneira exponencial a partir do advento da biologia molecular, especificamente, a partir da utilização de técnicas como sequenciamento do DNA ribossomal e hibridização DNA-DNA (Slepecky \& Hemphill, 2006). A última versão do Bergey's Manual of Systematic Bacteriology, publicada em 2012, contém 40 espécies reconhecidas. A Tabela 3, lista essas espécies, o conteúdo GC de cada uma e código de identificação da espécie depositada em coleções importantes.

Tabela 3. Composição básica do DNA e código de identificação em coleções importantes das diferentes cepas-tipo de espécies do gênero Bacillus.

\begin{tabular}{|c|c|c|c|c|c|c|c|}
\hline \multirow[t]{2}{*}{ Espécie de Bacillus } & \multicolumn{2}{|c|}{$\begin{array}{c}\text { Conteúdo CG } \\
(\mathrm{mol} \%)\end{array}$} & \multicolumn{5}{|c|}{ Código de identificação da espécie em coleções importantes } \\
\hline & $\mathrm{PF}^{\mathrm{a}}$ & $\mathrm{DF}^{\mathrm{b}}$ & $\mathrm{ATCC}^{\mathrm{d}}$ & DSM & NCIB & NCTC & NRRL \\
\hline acidocaldarius & 60,3 & 62,3 & 27009 & 446 & 11725 & & NRS1607 \\
\hline alcalophilus & 37,0 & 36,7 & 27647 & 485 & 10436 & 4553 & B14309 \\
\hline alvei & 44,6 & 46,2 & 6344 & 29 & 9371 & 6352 & B383 \\
\hline amylolyticus & $\mathrm{ND}^{\mathrm{c}}$ & 53,0 & & 3034 & & & NRS290 \\
\hline anthracis & 33,2 & ND & 14578 & & 9388 & 10340 & \\
\hline azotoformans & ND & 39,0 & 29788 & 1046 & & & B14310 \\
\hline badius & 43,8 & 43,5 & 14574 & 123 & 9364 & 10333 & NRS663 \\
\hline bBrevis & 47,3 & 47,4 & 8246 & 30 & 9372 & 2611 & NRS604 \\
\hline cereus & 35,7 & 36,2 & 14579 & 31 & 9373 & 2599 & B3711 \\
\hline circulans & 35,5 & 35,4 & 4513 & 11 & 9374 & 2610 & B380 \\
\hline coagulans & 47,1 & 44,5 & 7050 & 1 & 9365 & 10334 & NRS609 \\
\hline fastidiosus & 35,1 & 35,1 & 29604 & 91 & 11326 & & \\
\hline firmus & 41,4 & 40,7 & 14575 & 12 & 9366 & 10335 & NRS613 \\
\hline globisporus & 39,8 & 39,7 & 23301 & 4 & 11434 & & NRS1533 \\
\hline Insolitus & 35,9 & 36,1 & 23299 & 5 & 11433 & & \\
\hline Larvae & ND & 50,0 & 9545 & & & & B2605 \\
\hline laterosporus & 40,2 & 40,5 & 64 & 25 & 9367 & 6357 & NRS314 \\
\hline lautos & ND & $50-52$ & & 3035 & & & NRS666 \\
\hline lentimorbus & 37,7 & ND & 14707 & 2049 & 11202 & & B2522 \\
\hline lentus & 36,3 & 36,4 & 10840 & 9 & 8773 & 4824 & B396 \\
\hline licheniformis & 46,4 & 44,7 & 14580 & 13 & 9375 & 10341 & NRS1264 \\
\hline macerans & 52,2 & 53,2 & 8244 & 24 & 9368 & 6355 & B172 \\
\hline macquariensis & 39,3 & 41,6 & 23464 & 2 & 9934 & 10419 & B14306 \\
\hline marinus & 37,6 & 38,0 & 29841 & 1297 & & & B14321 \\
\hline megaterium & 37,3 & 37,6 & 14581 & 32 & 9376 & 10342 & B14308 \\
\hline mycoides & 34,2 & 34,1 & 6462 & 2048 & & & NRS273 \\
\hline pabuli & ND & $48-50$ & & 3036 & & & NRS924 \\
\hline pantothenicus & 36,9 & 36,8 & 14576 & 26 & 8775 & 8162 & NRS1321 \\
\hline pasteurii & 38,5 & 38,4 & 11859 & 33 & 8841 & 4822 & NRS673 \\
\hline polymyxa & 44,3 & 45,6 & 842 & 36 & 8158 & 10383 & NRS1105 \\
\hline popilliae & 41,3 & ND & 14706 & 2047 & & & В2309 \\
\hline psychrophilus & 39,7 & 40,5 & 23304 & 3 & & & NRS 1530 \\
\hline pumilus & 41,9 & 40,7 & 7061 & 27 & 9369 & 10337 & NRS272 \\
\hline schlegelii & 64,6 & 66,3 & 46741 & 2000 & & & \\
\hline sphaericus & 37,3 & 37,1 & 14577 & 28 & 9370 & 10338 & \\
\hline Subtilis & 42,9 & 43,1 & 6051 & 10 & 3610 & 3610 & NRS744 \\
\hline thermoglucosidasius & $45-46$ & ND & 43742 & 2542 & & & B15516 \\
\hline thurigiensis & 33,8 & 34,3 & 10792 & 2046 & 9134 & & NRS996 \\
\hline validus & ND & $53-54$ & & 3037 & & & NRS 1000 \\
\hline
\end{tabular}

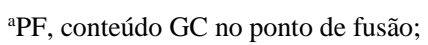

${ }^{b} \mathrm{DF}$, conteúdo GC em densidade de flutuação;

${ }^{\mathrm{C}} \mathrm{ND}$, não determinado;

${ }^{\mathrm{d} A T C C}$, American Type Culture Collection; DSM, Deutsche Sammlung von Mikroorganismen; NCIB, National Collection of Industrial Bacteria; NCTC, National Collection of Type Cultures; NRRL, Northern Regional Research Laboratory.

Fonte: Adaptado de Slepecky e Hemphill (2006). 
Existem hoje várias espécies validadas e publicadas como novas espécies do gênero Bacillus, contudo, estas são geneticamente e fenotipicamente diferentes das demais espécies do gênero e, por isso, não estão descritas no Bergey's Manual. Essas espécies incluem a bactéria B. pulvifasciens (Nakamura, 1984); B. alginolyticus e B. chrondrotinus, duas espécies com potencial de degradar algas (Nakamura, 1987); B. smithii (Nakamura et al., 1988); B. thermoleovorans, um organismo termofílico obrigatório com capacidade de metabolizar hidrocarbonetos (Zarilla \& Perry, 1987); B. benzoevorans, bactéria com capacidade de metabolizar ácidos aromáticos e degradar moléculas de fenol (Pichinoty et al., 1984) e a bactéria B. gordonae, organismo que degrada compostos aromáticos hidroxilados (Pichinothy et al., 1986).

A literatura contém inúmeros experimentos realizados com isolados de Bacillus que não foram ainda corretamente identificados como espécies do gênero, como, por exemplo, Bacillus sp. cepa SGI, um organismo manganês oxi-redutor (Johannes et al., 1986; Rosson \& Nealson, 1982); Bacillus sp. cepa C-59 e Bacillus sp. cepa N-6, ambos organismos alcalofílicos com propriedades bioenergéticas incomuns (Kitada \& Horikoshi, 1987; Kitada et al., 1989); Bacillus sp. cepa Gx6638, um organismo estável em altas temperaturas e condições de alcalinidade, com capacidade de secretar uma serinaprotease (Durham et al., 1987); Bacillus sp. cepa MGA3, uma bactéria termofílica, com capacidade de metabolizar o metanol e, a partir de mutações da cepa, produzir grandes quantidades do aminoácido lisina (Guettler \& Hanson, 1988; Schendel et al., 1989).

Quanto mais se aprofundam as pesquisas com o gênero Bacillus, mais se percebe o quão diverso o gênero é. Hunger \& Claus (1981) muito antes dos avanços e inúmeras técnicas moleculares hoje disponíveis, já demonstraram a grande variabilidade que existe entre espécies do gênero e inclusive, entre cepas de uma mesma espécie. As pesquisas desses autores mostraram que o conteúdo GC, importante critério taxonômico em procariotos, varia de 36 a $45 \%$ entre as cepas de $B$. megaterium. Dessa forma, a forma mais precisa para a classificação desses organismos se dá pelo sequenciamento do RNA ribossomal das espécies (Slepcky \& Hemphill, 2006).

\subsubsection{Sequenciamento do RNA ribossomal em Bacillus spp.}

A técnica mais efetiva utilizada para a taxonomia de microrganismos procariotos é o sequenciamento da região $16 \mathrm{~S}$ do RNA ribossomal (RNAr). O RNAr é o componente primário dos ribossomos das bactérias e essa molécula é transcrita a partir do DNA bacteriano, assim como todo RNA. A região $16 \mathrm{~S}$ é um componente da subunidade $30 \mathrm{~S}$ dos ribossomos bacterianos e se caracteriza por ser uma região altamente preservada e com baixas taxas de evolução, por isso, amplamente utilizada para a reconstrução filogenética das espécies (Fox et al., 1977; Stackebrandt \& Woese, 1979). Inicialmente, a utilização do sequenciamento da região $16 \mathrm{~S}$ como critério taxonômico, encontrou resistência entre os taxonomistas tradicionais, pois foi verificado que as espécies do gênero Bacillus estavam filogeneticamente correlacionadas com outras bactérias, mas essas últimas, não são formadoras de endósporos. Os primeiros estudos utilizando essa técnica molecular mostraram que as várias espécies de Bacillus apresentam alta correlação com as espécies Planococcus, Sporosarcina, Staphylococcus e Thermoactinomycetes (Stackebrandt et al., 1987; Stackebrandt \& Woese, 1981). Pesquisas mais recentes mostraram que a espécie B. subtilis e outras espécies formadoras de endósporos elipsoides, B. cereus, B. megaterium e $B$. pumilus, formam um grupo filogenético altamente correlacionado, enquanto as espécies formadoras de endósporos arredondados, B. sphaericus, B. glibisporus e B. aminovovorans, não. Além disso, esse último grupo é filogeneticamente correlacionado com organismos não esporogênicos (Slepcky \& Hemphill, 2006).

Atualmente, o sequenciamento da região $16 \mathrm{~S}$ do RNAr de espécies do gênero Bacillus, juntamente com estudos prévios utilizando a técnica molecular, possibilitou o rearranjo do gênero em três grupos distintos: I, II e III (Eppinger et al., 2011; Patiño-Navarrete \& Sanchis, 2016; Perchat et al., 2011; Slepcky \& Hemphill, 2006). Isso foi conseguido a partir do sequenciamento completo ou parcial da região $16 \mathrm{~S}$ do RNAr de 35 espécies que serviram como referência para o agrupamento, 
segundo metodologia proposta por Lane et al. (1985). As espécies parcialmente sequenciadas tiveram, pelo menos, 1.100 nucleotídeos determinados. Análises filogenéticas foram realizadas a partir de diferentes técnicas (Fitch \& Margoliash, 1967; Saitou \& Nei, 1987; Sneath \& Sokal, 1973), das quais resultaram os três grupos (grupos I, II e III), dispostos na Tabela 4.

Tabela 4. Clusters filogenéticos do gênero Bacillus organizados a partir de análises da região 16S do RNAr das espécies.

\begin{tabular}{|c|c|c|c|}
\hline Grupo morfológico & Cluster I: B. subtilis & Cluster II: B. alvis & Cluster III: B. brevis \\
\hline I & $\begin{array}{l}\text { B. subtilis, } B . \text { cereus, } B . \\
\text { licheniformis, B. pumilus, } B . \\
\text { megaterium cepa Mohb, } B . \\
\text { coagulans, B. smithii }\end{array}$ & & \\
\hline II & $\begin{array}{l}\text { B. circulans, B. larvae, B. } \\
\text { stearothermophilus }\end{array}$ & $\begin{array}{l}\text { B. alvei, } B . \text { polymyxa, } B . \\
\text { macerans, } \text { B. azotofixans, } \\
\text { B. pulvifaciens }\end{array}$ & B. brevis, B. laterosporus \\
\hline III & B. sphaericus & & \\
\hline Subgrupo A & B. thiaminolyticus, B. alcalophilus & & \\
\hline Subgrupo B & B. lentus & & \\
\hline Subgrupo C & B. freudenreichii, B. aneurinolyticus & & \\
\hline Subgrupo D & B. pantothenicus & & \\
\hline Subgrupo E1 & B. psychrophilus, B. insolitus & & \\
\hline Subgrupo E2 & & B. macquariensis & \\
\hline
\end{tabular}

Fonte: Modificada de Slepecky e Hemphill (2006).

O agrupamento das espécies de Bacillus em grupos, após as análises da região 16S do RNAr, foi diferente daquilo que foi proposto nos estudos iniciais de Stackebrandt et al. (1987). Com exceção do grupo morfológico II, todas as cepas sequenciadas foram agrupadas no cluster I da espécie B. subtilis. Cepas de Bacillus do grupo morfológico II, foram reagrupadas nos três clusters filogenéticos e a espécie B. macquariensis, diferentemente de outros organismos psicrófilos (resistentes a baixas temperaturas), foi inserida no cluster II da bactéria B. alvei (Tabela 4) (Eppinger et al., 2011; PatiñoNavarrete \& Sanchis, 2016; Perchat et al., 2011; Slepcky \& Hemphill, 2006).

Análises comparativas da região $16 \mathrm{~S}$ de cepas bacterianas termofílicas e psicrófilas de Bacillus mostraram que, os organismos termofílicos B. stearothermophilus, B. thermodenitrificans e B. caldotenax formam um subgrupo dentro do cluster de B. subtilis, mas este é separado das cepas termotolerantes mesofílicas de B. subtilis e B. licheniformis e da bactéria moderadamente termofílica B. coagulans. As cepas psicrofílicas, B. psychrophilus e B. insolitus, estão classificadas no cluter I, enquanto B. macquariensis está inserida no cluster II.

Conforme estudos mais acurados são feitos com indivíduos pertencentes ao gênero, novas realocações nos clusters serão necessárias. A taxonomia de procariotos é extremamente variável e provavelmente, novas espécies serão descobertas e por isso, atualizações nesse aspecto serão sempre requeridas.

\subsection{As bactérias endófitas Bacillus spp. como potenciais agentes de biocontrole}

Bactérias endófitas são entendidas por Kado (1992) como aquelas que vivem nos tecidos das plantas sadias sem causarem danos ou receberem outros benefícios significativos que não seja abrigo. Dos muitos microrganismos encontrados em associação endofítica com plantas, bactérias são dos mais frequentes (Romeiro, 2007). Em estudo realizado por McInroy \& Kloepper (1995), que objetivou verificar a pluralidade de bactérias endofíticas em associação com raízes e caules de milho e algodão no estado do Alabama, EUA, foram obtidos isolamentos de bactérias pertencentes a 36 gêneros distintos, sendo 70,5\% deles compostos de espécies Gram-negativas. Entre as muitas espécies encontradas, os autores mencionaram Burkholderia, Enterobacter, Bacillus, Methylobacterium, Agrobacterium, Serratia, Acinetobacter, Arthrobacter e Pseudomonas. Outro 
estudo, realizado no Canadá, por Germida et al. (1998) isolou e identificou 220 bactérias endofíticas de canolas e as análises de ácidos graxos da parede celular (fatty acid analysis), permitiram aos pesquisadores concluir que a maioria dos isolamentos pertencia a 18 gêneros de bactérias, com predominância (73\%) de quatro principais: Bacillus (29\%), Flavobacterium (12\%), Micrococcus (20\%) e Rathayibacter (12\%).

Microrganismos endófitos têm sido isolados da maioria das plantas cultivadas (Musson, 1994). Provavelmente, isso se aplica também a plantas silvestres.

Relatos de isolamento de bactérias endófitas a partir de plantas sadias já existem há mais de cinquenta anos. Já na década de 1940, Hennig e Villforth (1940) relataram isolamento de bactérias de órgãos sadios de 28 plantas diferentes, como tomate, gerânio, repolho e rabanete. Também Tervet e Hollis (1948) mencionam ter isolado bactérias endofíticas de órgãos de reserva sadios, como batata, beterraba, batata-doce, assim como de frutos de tomate. Pettit et al. (1968) foram capazes de isolar B. subtilis do interior de vagens sadias de amendoim.

Há multiplicidade de relatos a respeito do isolamento de bactérias endófitas em gramíneas e outras monocotiledôneas (Azevedo et al., 2000; Kungel; Grewal, 2003; Mcneil et al., 2003; Riggs et al., 2001; Scott \& Young, 2003; Yanni et al., 2001). Há também inúmeros relatos de bactérias endofíticas em associação com árvores e plantas lenhosas (Bettucci et al., 1997; Cankar et al., 2005; Mcafee \& Taylor, 2001; Redlin \& Carris, 1996; Schulthess \& Faeth, 1998; Smith et al., 1996). A maioria das pesquisas, contudo, é voltada para plantas agronômicas e olerícolas (Bouton \& Hopkins, 2003; Cavaglieri et al., 2004; Coombs \& Franco, 2003; Coombs et al., 2004; El-Tarabily, 2003; Sturz \& Kimpinski, 2004; Zinniel et al., 2002).

É possível que toda planta possa, potencialmente, abrigar bactérias endofíticas em seus tecidos sadios. Hoje é sabido que alguns desses endófitas agem como agentes de biocontrole de enfermidades ou como promotores de crescimento, ainda que a maioria deles não exiba qualquer efeito detectável ou sejam, até mesmo, deletérios (Hallmann et al., 1997; Musson, 1994).

Espécies do gênero Bacillus podem ser aplicadas de forma a controlar biologicamente enfermidades nos vegetais, sendo também, verificado o efeito positivo desse grupo de procariotos sobre a produtividade das lavouras (Ngugia et al., 2005; Yao et al., 2006). Promoção de crescimento e controle biológico podem ser verificados no campo de produção a partir da aplicação de cepas de B. subtilis (Hammami et al., 2009). O antagonismo promovido pela bactéria se dá tanto direta quanto indiretamente (Ryu et al., 2004; Ongena et al., 2007; Leelasuphakul, 2008). Os efeitos diretos observado sobre os patógenos de plantas, envolve antibiose, competição por espaço e nutrientes, além da produção de compostos orgânicos voláteis, extremamente nocivos às espécies que se quer controlar (Leelasuphakul, 2008). Indiretamente, as bactérias promovem o fortalecimento das defesas do vegetal através do fenômeno da resistência sistêmica induzida (Lanna Filho et al., 2010). Dessa maneira, produtos formulados a partir de cepas de B. subtilis são, geralmente, lançados com a informação de "produto de amplo espectro de ação", devido às múltiplas maneiras que esses organismos têm de interagir e interferir o organismo-alvo.

\subsubsection{Modos de ação de células de Bacillus aplicadas ao biocontrole de doenças em plantas}

\subsubsection{Ação indireta: resistência sistêmica induzida (ISR)}

Em condições naturais, as plantas apresentam mecanismos de defesa contra o ataque de patógenos que funcionam como barreiras à infeção. Trata-se de um processo morfológico e bioquímico, coordenado por uma cascata de eventos inscritos no genoma da planta e que podem ocorrer de forma anterior e/ou posterior à interação com o agente patogênico (Alves, 2007; Kiraly et al., 1997). Os mecanismos de defesa ativados após o contato com o patógeno podem, em muitas vezes, ser ativados por moléculas e compostos bioativos (Choudhary et al., 2007). A atividade bioquímica pós-formada em plantas é de amplo espectro de ação e se apresenta, muitas vezes, na forma de resistência sistêmica adquirida (SAR) e resistência sistêmica induzida (ISR), dois processos que podem ter como estopim a interação com microrganismos, não necessariamente sendo 
estes, patógenos. (Pieterse; Van Loon, 2004). Os dois fenômenos são regulados pela proteína NPR1 e, no momento da expressão do gene que codifica essa proteína há um crosstalk (comunicação cruzada) entre os processos e subsequene ativação das respostas de defesa (Choudhary et al., 2007; Pieterse; Van Loon, 2004). Um fato curioso acerca do processo é que mesmo sendo um fenômeno que implique em resposta de resistência por parte do vegetal, as rotas de sinalização na SAR e na ISR são distintas entre si. Na primeira, há ampla participação do ácido salicílico; na segunda, o ácido jasmônico e o hormônio etileno são as moléculas ativadoras da defesa vegetal. A Figura 2 exemplifica bem os caminhos para a sinalização da resistência e os agentes indutores de cada fenômeno em plantas.

Figura 2. Esquema ilustrativo da indução de resistência em plantas. À esquerda, a resistência sistêmica adquirida (SAR), ativada por patógenos biotróficos virulentos ou não, não patógenos e rizobactérias, acontece pela rota do ácido salicílico; à direita, a resistência sistêmica induzida (ISR), ativada por rizobactérias promotoras de crescimento, insetos e patógenos necrotróficos, ativa as rotas do ácido jasmônico e/ou etileno.

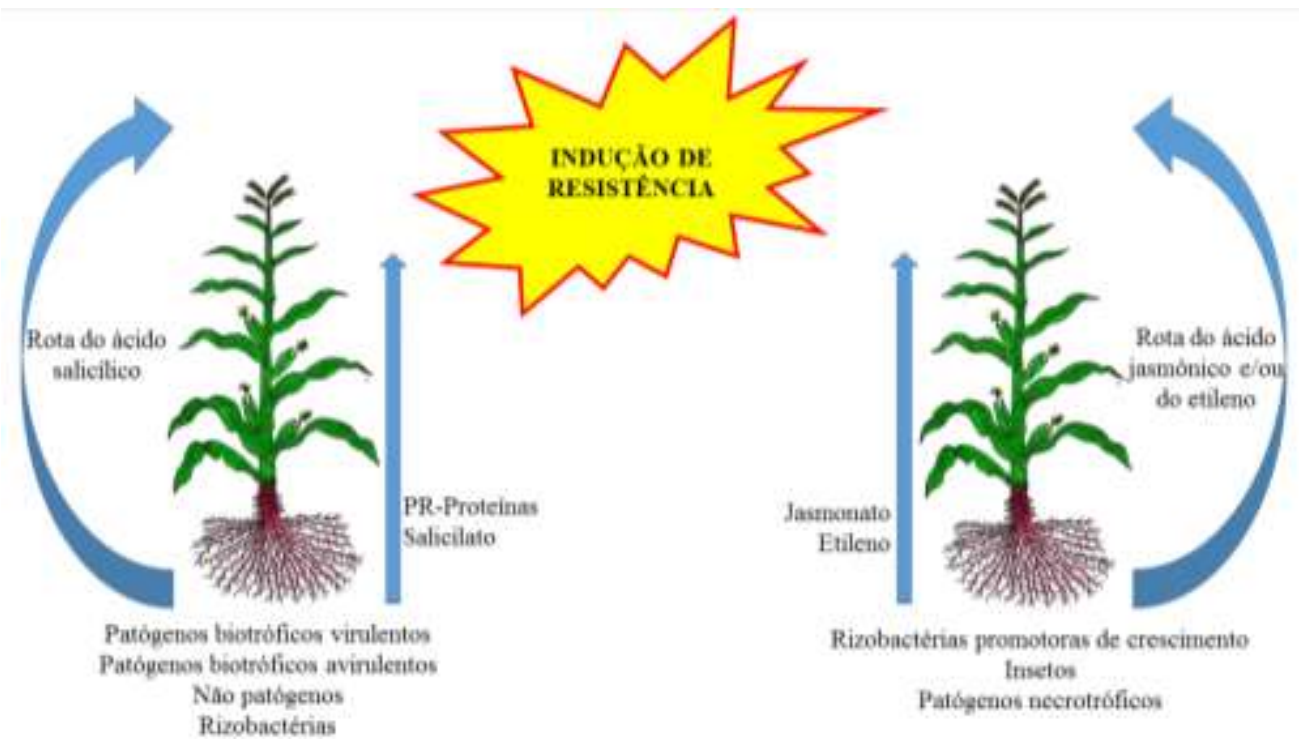

Fonte: Extraído de Pascholati et al. (2015).

Na resistência sistêmica induzida (ISR) o que está posto é que esta pode ser ativada tanto por patógenos, organismos não patógenos e produtos do metabolismo de ambos (Pieterse; Van Loon, 2004; Romeiro, 2007; Pascholati, 2011). Dessa forma, moléculas produzidas por espécies distintas de Bacillus podem interferir diretamente da defesa vegetal, gerando sistemicidade de resposta e resposta inespecífica a uma ampla gama de agente fitopatogênicos (Ryu et al., 2004; Ongena et al., 2007). Estudando a produção de lipopeptídeos da família das surfactinas e fengicinas, Ongena et al. (2007) determinaram, geneticamente, que o isolado 168 de B. subtilis induzia de respostas de defesa sistêmica em tomateiros e feijoeiros. Respostas como a encontrada por esses autores demonstram que trabalhos de bioprospecção de novas moléculas atreladas às diferentes cepas de Bacillus é uma seara ampla no contexto da ativação de genes de defesa vegetal, em diferentes fases da vida da planta (Lanna Filho et al., 2010).

Ainda, compostos orgânicos voláteis podem apresentar um papel importante na indução de resistência. Tal fenômeno já foi observado em Arabdopsis submetidas ao tratamento com compostos orgânicos voláteis produzidos pela cepa GB03 de $B$. subtilis, em interação com o microrganismo alvo Pectobacterium carotovorum subsp. carotovorum, bactéria pectinolítica de grande interesse econômico para o manejo de doenças na fase de pós-colheita (Ryu et al., 2004). 


\subsubsection{Ação direta: síntese de metabólitos}

Agentes de biocontrole, como as bactérias do gênero Bacillus, apresentam significativa atividade antibiótica, podendo, algumas vezes, agir como parasitas, em processos de hiperparasitismo, ou como excelentes competidoras (Lanna Filho et al., 2010). A atividade antibiótica desses organismos é, quase sempre, bastante intensa, não sendo necessárias grandes doses da molécula controladora para que os efeitos sejam percebidos (Kupper et al., 2003).

Isolados de Bacillus, de diferentes espécies, sintetizam uma enorme quantidade de moléculas com propriedades antimicrobianas, entre os quais se encontram lipopeptídeos das famílias da surfactina, iturina e fengicina (Ongena et al., 2005). Alguns dos genes bacterianos que carregam a informação genética para a produção dessas substâncias já foram mapeados e outros já foram, inclusive, clonados (Ivanova et al., 2003; Kunst et al., 1988; Raajimakers et al., 2010; Stein, 2005). Contudo, para a maioria das moléculas antibióticas produzidas por espécies de Bacillus, essas informações ainda são desconhecidas. A Tabela 5 apresenta alguns dos antibióticos produzidos por Bacillus spp. e se essas moléculas já tiveram os genes que as codificam mapeados e clonados.

Tabela 5. Alguns antibióticos produzidos por espécies de Bacillus.

\begin{tabular}{|c|c|c|c|}
\hline Espécies & Antibiótico & Mapeamento gênico & Clonagem dos genes \\
\hline \multirow[t]{7}{*}{ B. subtilis } & Subtilina $^{\mathrm{a}}$ & + & + \\
\hline & Surfactina ${ }^{\mathrm{b}}$ & + & - \\
\hline & Bacilisina $^{\mathrm{a}}$ & + & - \\
\hline & Dificidina $^{c}$ & - & - \\
\hline & Oxydificidina $^{c}$ & - & - \\
\hline & Bacilomicina $\mathrm{F}^{\mathrm{d}}$ & - & - \\
\hline & Micobacilina $^{\mathrm{d}}$ & - & - \\
\hline \multirow[t]{3}{*}{ B. brevis } & Gramicidina As & + & + \\
\hline & Lincar gramicidina $^{\mathrm{a}}$ & - & - \\
\hline & Tirocidina $^{\mathrm{a}}$ & + & + \\
\hline \multirow[t]{2}{*}{ B. licheniformis } & Bacitracina $^{a}$ & + & + \\
\hline & Proticina & - & - \\
\hline \multirow[t]{2}{*}{ B. pumilus } & Pumilina $^{\mathrm{a}}$ & - & - \\
\hline & Tetaína & - & - \\
\hline B. mesentericus & Esperina $^{\mathrm{a}}$ & - & - \\
\hline \multirow[t]{2}{*}{ B. polymyxa } & Polymycina $^{\mathrm{e}}$ & - & - \\
\hline & Colistina $^{\mathrm{e}}$ & - & - \\
\hline \multirow[t]{2}{*}{ B. thiaminolyticus } & Octoptina $^{\mathrm{a}}$ & - & - \\
\hline & Baciphelacina $^{\mathrm{a}}$ & - & - \\
\hline \multirow[t]{2}{*}{ B. circulans } & Circulina $^{\mathrm{e}}$ & - & - \\
\hline & Butirosina $a^{e}$ & - & - \\
\hline \multirow{2}{*}{ B. laterosporus } & Laterospuramina $^{\mathrm{e}}$ & - & - \\
\hline & Laterosporina $^{\mathrm{a}}$ & - & - \\
\hline \multirow[t]{2}{*}{ B. cereus } & Biocerina $^{a}$ & - & - \\
\hline & Cerexina $^{\mathrm{a}}$ & - & - \\
\hline
\end{tabular}

${ }^{a}$ Efetivo contra bactérias Gram-positivas

${ }^{\mathrm{b}}$ Inibidor da coagulação da fibrina

${ }^{\mathrm{c} A n t i b i o ́ t i c o ~ d e ~ a m p l o ~ e s p e c t r o ~}$

dAção antifúngica

effetivo contra bactérias Gram-negativas

Fonte: Modificada de Slepecky e Hemphill (2006); Bleich et al. (2015).

Grande parte das moléculas antimicrobianas produzidas por B. subtilis são moléculas cíclicas que apresentam sete ou dez $\alpha$-aminoácidos ligados a um único $\beta$-amino (iturinas) ou $\beta$-hidroxi (surfactinas e fengicinas) ácido graxo. O comprimento da cadeia de ácidos graxos pode variar de C13 a C16 para surfactinas, de C14 a C17 para iturinas e de C14 a C18, no caso de fengicinas (Ongena et al., 2005).

Apesar de serem moléculas de estrutura química muito parecida, surfactinas, iturinas e fengicinas diferem entre si no 
que diz respeito à atividade antimicrobiana. Iturinas e fengicinas são moléculas fungistática e/ou fungicidas, dependendo da dose utilizada, sendo também agentes de inibição inespecífica a um número significativo de patógenos de plantas (Lanna Filho et al., 2010). Em relação às surfactinas, tem-se nesse grupo moléculas que são, essencialmente, fungitóxicas, mas que também carregam algum efeito sinergístico antifúngico, quando associadas à iturina A (Maget-Dana et al., 1992). Sobre bactérias fitopatogênicas, as surfactinas são compostos de baixa interferência sobre o metabolismo procariótico, diferente do observado pelas itaurinas, que têm alto poder inibitório sobre bactérias Gram-positivas.

O biocontrole de Pseudomonas syringae em Arabdopsis por B. subtilis, deu-se a partir de uma estirpe mutante, M1, com uma deleção do gene surfactina sintase e, portanto, deficiente na produção de surfactina (Bais et al., 2004). Os autores mostraram que a bactéria $B$. subtilis M1 não foi eficiente enquanto agente biocontrolador, inclusive, por não ser capaz de produzir um biofilme protetor nas raízes da planta. A partir dos resultados obtidos nos ensaios, os autores afirmaram que o perfil antagônico do isolado e a sua capacidade de formar biofilme são grandezas diretamente proporcionais à síntese da surfactina.

Alguns trabalhos demonstraram que espécies de Bacillus são capazes de produzir substâncias voláteis com atividade antimicrobiana, mas, muitas dessas substâncias voláteis produzidas por esses microrganismos são ainda desconhecidas (Kai et al., 2007). Chen et al. (2008) encontraram 14 compostos voláteis de B. subtilis, identificados através de cromatografia gasosa de espectro de massa (CG-MS), com aparente fonte de compostos bioativos. A natureza antifúngica de alguns compostos, tais como 2-etil-hexanol, 2,4-bis-(2-metilpropril)-fenol, 4-hidroxibenzaldeído e 2-nonanona, foi também demonstrada em outros patossistemas (Wang et al., 2004; Almenar et al., 2007).

Não há trabalhos disponíveis na literatura que atestem o efeito isolado dessas moléculas sobre fitonematoides, entretanto, Voss (2013) aplicando diferentes concentrações de suspensão de células de B. subtilis em tomateiros parasitados por Meloidogyne incognita, verificou efeito dos tratamentos na diminuição gradativa da população do patógeno no solo quanto maior foi a concentração de células aplicada. Moléculas específicas atuam no controle biológico de nematoides a partir de células de Bacillus. Informações mais detalhadas a respeito desse assunto serão apresentadas e discutidas em seção específica desta revisão.

\subsubsection{Promoção de crescimento em plantas}

A promoção de crescimento gerada por espécies do gênero Bacillus é consequência do aumento da fixação de nitrogênio, solubilização de nutrientes, síntese de fitormônios e melhoria das condições de solo, além disso, existem também os benefícios indiretos gerados pela modificação do ambiente, fato que pode interferir no desenvolvimento de fitopatógenos (Manjula \& Podile, 2005). Adicionalmente, as associações benéficas entre as espécies de Bacillus e as plantas modulam a fisiologia destas últimas, desencadeando o aumento de metabólitos que sensibilizam o sistema radicular às condições externas do meio, proporcionando, inclusive, maior capacidade vegetal de absorção de nutrientes (Manjula \& Podile, 2005). Isolados de B. subtilis têm capacidade comprovada de conduzir a regulação hormonal de plantas, como relatado por Tsavkelova et al. (2006) e Persello-Cartieaux et al. (2003), conduzindo assim, o crescimento radicular pela síntese de auxinas, giberelinas e citocininas.

A promoção de crescimento induzida por espécies de Bacillus pode levar a semente à rápida germinação. Isso foi constatado em estudos realizados por Manjula \& Podile (2005) que, tratando sementes de feijão guandu com formulação à base de $B$. subtilis AF1 em turfa suplementada com quitina, verificaram um aumento da emergência e do peso fresco das mudas de 29 e 33\%, respectivamente. Araújo (2008), tratando sementes de algodão, milho e soja com um bioformulado à base de $B$. subtilis PRBS1 também verificaram incrementos na emergência de plântulas. Assim, o rápido desenvolvimento da planta, quando na presença da bactéria, a leva a chegar na fase adulta rapidamente, permanecendo menos tempo no campo, e também, 
menos tempo em uma condição de maior suscetibilidade, gerando assim, um escape contra patógenos presentes no solo e no ambiente externo. Considerando o fator nutricional, a associação de espécies de Bacillus com plantas promove maior resistência vegetal às condições abióticas adversas, pois as plantas se apresentam nutricionalmente balanceadas.

\subsubsection{Aplicação de espécies de Bacillus no controle biológico de fitonematoides}

Os nematoides são o segundo filo do reino animal, ficando atrás apenas dos insetos, com maior número de representantes. Apesar de tamanha representatividade, apenas 3\% do total de espécies de nematoides existentes em todo o mundo vêm sendo estudadas e estão identificadas (Ravichandra, 2014). Um metro cúbico de solo pode conter milhões desses vermes pertencentes a diferentes grupos taxonômicos. Os representantes fitoparasitas são microscópicos, em sua maioria, com formato cilíndrico ou vermiforme, virtualmente invisíveis a olho nu e são habitantes de diferentes ambientes, sendo o solo o local com o maior número de espécies de importância econômica para a agricultura (Handoo, 1998).

Os fitonematoides podem causar danos de intensidade variável nas plantas hospedeiras. Estes danos podem ser pequenas injúrias ou, até mesmo, a destruição de toda a planta. A severidade da injúria causada pela atividade de um helminto fitoparasita é dependente de vários fatores e, dentre estes, destaca-se a espécie do fitonematoide e a associação desta com a planta hospedeira, além das condições ambientais, como os níveis pluviométricos da região, o tipo de solo, a conformação do relevo e as demais culturas praticadas ou plantas presentes na área.

Em função do habitat preferencial da maioria das espécies, o solo, os nematoides se constituem em uma das espécies parasitas de plantas de identificação, demonstração e manejo mais difícil. Frequentemente, os danos causados em plantas por esses vermes passam despercebidos devido, em muito, à sintomatologia não específica que as plantas parasitadas apresentam. Dentre os sintomas mais comuns encontrados nas plantas e que podem levar ao diagnóstico errôneo de uma doença causada por fitonematoides, estão o crescimento lento do vegetal, o nanismo e o amarelecimento de folhas, sintomas que podem, facilmente, ser confundidos com deficiências nutricionais e hídricas (Stirling et al., 1998). O efeito desses parasitas nas culturas é, geralmente, subestimado pelos produtores e agrônomos, mas a estimativa é de que os fitonematoides sejam responsáveis pela perda de 10\% de toda a produção mundial, algo em torno de 100 bilhões de dólares (Whitehead, 1998; Freitas et al., 2001; Ravichandra, 2014).

Sendo o controle de fitonematoides uma tarefa difícil, o mais recomendado é o uso de técnicas conjuntas para o eficiente manejo das fitonematoses. O controle químico através de nematicidas apresenta vários inconvenientes, pois esses produtos são caros, altamente tóxicos, persistentes, têm amplo espectro de ação e podem contaminar águas subterrâneas, representando, dessa forma, um grande risco a outros organismos e ao ambiente (Monteiro, 1970; Ferraz \& Valle, 1997).

Uma alternativa promissora ao uso dos agrotóxicos tem sido a utilização do controle biológico, juntamente com outras técnicas de manejo de doenças de plantas (Nunes et al., 2010). O controle biológico trata da redução de fitonematoides por outro organismo vivo. Ele pode ocorrer naturalmente ou ser induzido. Os microrganismos do solo de diferentes zonas agrícolas são muito numerosos e estão em constante associação, o que resulta em um balanço biológico natural. O parasitismo de fitonematoides em plantas hospedeiras é afetado em diferentes intensidades, dependendo da densidade e das espécies de microrganismos presentes no solo de determinado campo na rizosfera das plantas ali cultivadas. Os mecanismos de controle

biológico do organismo antagonista ao nematoide, assim como nos outros casos de controle biológico clássico, são: parasitismo, predação, competição e antibiose.

Segundo Pascholati (2011), para que um microrganismo seja considerado um bom agente de controle biológico, ele deve possuir vários atributos, dentre os quais os mais importantes são:

- Não ser patogênico a plantas, seres humanos e outros animais;

- Ser eficiente em reduzir ou suprimir a população de nematoides em alta densidade; 
- Sobreviver a condições extremas no solo, na ausência do hospedeiro;

- Parasitar diversas espécies de fitonematoides;

- Ser capaz de se disseminar assim que aplicado ao solo, garantindo o seu estabelecimento;

- Ser fácil e economicamente produzido em massa;

- Permanecer infectivo após longo tempo de armazenamento;

- Ser compatível com fertilizantes, defensivos químicos e outras práticas culturais.

As bactérias do gênero Bacillus apresentam grande parte dessas características e são amplamente aplicadas no manejo de fitonematoides (Araújo et al., 2002; Nunes et al., 2010; Vaz et al., 2011).

Hallmann et al. (2004) sugerem que bactérias endofíticas apresentam potencial para o controle de fitonematoides, principalmente endoparasitas. Partindo desse princípio, várias pesquisas já foram conduzidas. Sikora e Padgham (2007) relataram redução de $40 \%$ na penetração e formação de galhas de Meloidogyne graminicola com inoculações de $B$. megaterium nas raízes de arroz. Além disso, a colonização da bactéria no sistema radicular da planta diminuiu em $60 \%$ a migração do nematoide para a rizosfera e seus metabólitos reduziram em $60 \%$ a eclosão de ovos. Sikora (1992), relatou que bactérias da rizosfera reduzem o nível de danos de nematoides a partir da liberação de toxinas ou modificação dos exudatos radiculares, sendo de fácil crescimento in vitro, além de poderem ser aplicadas no tratamento de sementes.

A espécie Heterodera glycines, formadora de cisto, constitui-se em um dos fitonematoides de maior importância econômica para a cultura da soja. Ao longo do ciclo de vida dessa espécie, o cisto se rompe liberando uma grande quantidade de ovos, que dependem de estímulos gerados pela liberação de exsudatos da planta para a eclosão e orientação das larvas (J2). Assim, o trabalho de Araújo et al. (2002) verificou a influência de B. subtilis na eclosão, orientação e infecção de $H$. glycines em soja, in vitro e in vivo. Em condições de laboratório, os autores verificaram que a presença da bactéria inibe a eclosão de ovos do nematoide, mesmo na presença de exsudatos de soja. Além disso, raízes tratadas com a bactéria foram menos atrativas aos vermes que as não tratadas. Em condições de casa de vegetação, houve redução de fêmeas em vasos infestados com o nematoide quando o solo ou as sementes foram tratadas previamente com suspensão de B. subtilis.

Em outro trabalho realizado por Araújo \& Marchesi (2009) a utilização de B. subtilis em tomateiros trouxe múltiplos benefícios para a planta. Os autores relataram que, embora a altura da planta não tenha sido influenciada pela presença da rizobactéria no solo, a produção de massa fresca da parte aérea foi incrementada pelo tratamento com a bactéria. Houve, de maneira inversa ao observado para a parte aérea, redução da produção de massa fresca das raízes dos tomateiros. Isso se deu, provavelmente, porque rizobactérias e seus metabólitos desencadeiam reações de hipersensibilidade nas células vegetais, resultando em um menor volume de raiz (Freitas et al., 2001). Adicionalmente, raízes parasitadas por fitonematoides são, geralmente, mais volumosas que raízes não parasitadas (Ferraz \& Valle, 1997). Tal aspecto funciona como um processo de substituição da raiz danificada pelo parasitismo do helminto por uma nova raiz, ora livre do verme e capaz de exercer todas as suas funções. Foi exatamente o que foi observado por Araujo \& Marchesi (2009). Embora o a massa fresca radicular tenha sido menor, o efeito do tratamento biológico sobre a reprodução de Meloidogyne spp. foi evidente na redução do número de juvenis e no desenvolvimento de massas de ovos na raiz. Segundo Maciel \& Ferraz (1996), o método biológico para o controle de nematoides pode acontecer pela paralização do ciclo ou, pelo menos, pela redução da capacidade reprodutiva do parasita. Além disso, a transformação dos exsudatos radiculares em subprodutos pela ação dos microrganismos, pode fazer com que o nematoide não reconheça o estímulo quimiotrópico e continue movimentando-se no solo até morrer (Freitas, 2001).

Ludwig et al. (2013) relataram o potencial de rizobactérias utilizadas para a microbiolização de sementes de arroz em controlar o nematoide $M$. graminicola. Nos testes realizados, os isolados bacterianos utilizados, entre eles, dois isolados de Bacillus sp., reduziram significativamente a eclosão de ovos do nematoide e aumentaram a mortalidade de larvas de segundo estágio (J2). Além disso, a associação das bactérias com as plantas de arroz culminou com a ativação dos mecanismos de 
defesa vegetal, verificado pelo aumento da atividade das enzimas quitinases, fosfatases, lipases e proteinases. Isso refletiu diretamente na redução do número de galhas e ovos nas plantas tratadas e redução de $29 \%$ do fator de reprodução do nematoide.

Em contrapartida, existem alguns trabalhos disponíveis na literatura que demonstram que a utilização de espécies de Bacillus pouco interferem ou não interferem no parasitismo de fitonematoides. O trabalho de Vaz et al. (2011) é um exemplo disso. Os autores microbiolizaram sementes de tomate com a bactéria B. subtilis, produziram mudas a partir destas e transplantaram essas mudas para vasos contendo uma população mista de $M$. incognita e $M$. javanica. O controle do teste foi composto por mudas advindas de sementes mergulhadas em água e também, mudas produzidas a partir de sementes não mergulhadas. Após 60 dias do transplantio, foram avaliados os parâmetros massa das raízes e parte aérea, número de galhas e ovos. O que se observou foi que não houve interferência da microbiolização das sementes em nenhum dos parâmetros avaliados, em relação aos controles. Em experimento semelhante, Fernandes et al. (2014) verificaram também que a microbiolização de sementes de tomateiro não interferiu na massa fresca da raiz e da parte aérea de tomateiros parasitados por M. incognita e $M$. javanica, tampouco reduziu o número de galhas nas raízes, quando em comparação com o controle. Contudo, diferentemente dos autores citados anteriormente, neste caso, os autores verificaram redução de 62,6\% do número de ovos em sementes microbiolizadas. Além disso, a combinação da microbiolização de sementes e a utilização do fungo Pochonia chlamydosporia no solo reduziu, em mais de 80\%, o número de ovos de Meloidogyne spp. que a utilização da microbiolização enquanto método isolado.

As diferentes respostas observadas em experimentos semelhantes, são devidas a inúmeros fatores, dentre os quais, pode-se destacar o número de células bacterianas no inóculo que ainda estão viáveis no momento do tratamento, o tempo de exposição das plantas ou sementes ao inóculo (no caso da microbiolização), as condições ambientais nas quais os testes são conduzidos, o grau de agressividade do patógeno utilizado e também, o nível de resistência do hospedeiro escolhido para os testes, sendo requeridas, sempre que possível, variedades de plantas com alto grau de suscetibilidade.

Trabalhos mais recentes estão focados em determinar e purificar os compostos produzidos pelo metabolismo secundário de Bacillus com atividade nematicida. O trabalho realizado por Xiong et al. (2015) é um exemplo disso. Os autores verificaram o efeito de compostos bioativos produzidos por um isolado de Bacillus firmus e a capacidade destes de controlar o nematoide das galhas, M. incognita. Em um teste que verificou a movimentação de larvas J2 do verme fitoparasita em colunas de areia, os autores observaram que a utilização de frações proteicas não purificadas, produzidas pela bactéria, diminuiu a movimentação da larva. Além disso, a utilização dessas frações proteicas nas doses de 20, 40, 80, 100, 150 e $200 \mu \mathrm{L} / \mathrm{mL}$ teve forte efeito nematicida sobre as larvas, sendo este, na ordem dos 40,2\%, 51,1\%, 66,8\%, 79,8\%, 89,3\% e 96,8\%, respectivamente.

A espécie B. thurigiensis é uma bactéria esporogênica presente em, praticamente, todos os lugares e que produz cristais proteináceos de prototoxinas (chamados de proteína cristal ou proteína-Cry), durante a esporulação (LI et al., 2015). As proteínas-Cry têm atividade específica de toxina em lagartas, besouros e nematoides, mas não afeta vertebrados, por isso, $B$. thurigiensis tem sido descrito por muitos pesquisadores como um biopesticida ideal. Em 1972, Prasad et al. (1972) atestaram, pela primeira vez, que populações de $M$. incognita foram significativamente reduzidas pelo tratamento de plantas com a bactéria $B$. thurigiensis var. thurigiensis. Desde então, inúmeros estudos demonstraram o sucesso da aplicação dessa bactéria no controle de nematoides fitopatogênicos na agricultura orgânica. Adicionalmente, os genes relacionados com a produção das proteínas-Cry estão em pleno uso em plantas transgênicas sendo, estas últimas, amplamente utilizadas em todo o mundo para a proteção das lavouras contra os nematoides (Li et al., 2007; Sanahuja et al., 2011).

Atualmente, têm-se o conhecimento de três famílias de proteínas-Cry com atividade nematicida, são elas: (1) a família Cry5 que contém as proteínas Cry5, Cry12, Cry13, Cry14 e Cry21, (2) a família Cry6 com a proteína Cry6 e (3) a família 
Cry55 com a proteína Cry55 (LI et al., 2007; LUO et al., 2013; WEI et al., 2003). A proteína Cry5B é a proteína mais estudada (DURMAZ et al., 2016; KOCH et al., 2016; WU et al., 2015). Após investigações e diversos testes utilizando larvas de nematoides de diferentes espécies, foi constatado que a proteína Cry5B interage com receptores específicos presentes na membrana intestinal do helminto, resultando na formação de poros líticos e, consequentemente, tal interação resulta na lise do intestino do verme e posterior morte do organismo (Griffitts et al., 2005; Vachon et al., 2012). Diferentemente da proteína Cry5B, a proteína CryAa2 causa prejuízos de ordem fisiológica para o nematoide, como observado na espécie Caenorhabditis elegans, nematoide bacteriófago e decompositor da matéria orgânica morta. As pesquisas constataram, nesse caso, inibição do crescimento do verme, redução no número de ovos produzidos e, redução na capacidade de movimentação do parasita (Luo et al., 2013). A combinação das duas proteínas, Cry5B e CryAa2, resultou em um efeito sinergístico sobre C. elegans, demonstrando que estas proteínas podem se constituir em uma potente estratégia de biocontrole contra nematoides fitoparasitas (Yu et al., 2014).

Objetivando encontrar novas proteínas-Cry, os genomas de várias cepas de B. thurigiensis já foram sequenciados e três genes codificantes de proteínas-Cry, pertencentes ao grupo Cry21, foram identificados no genoma da cepa DB27 (Iatsenko et al., 2014). É importante mencionar que a produção de uma proteína-Cry pela bactéria é sempre acompanhada por um fator de virulência com atividade nematicida, o que potencializa a ação da proteína (Niu et al., 2010). Além disso, a atividade patogênica da bactéria $B$. thurigiensis é restrita a um estreito grupo de insetos e nematoides, não interfere, portanto, sobre em homens e outros animais (Li et al., 2015). Outra informação relevante é que cepas de B. thirigiensis são, geralmente, altamente suscetíveis a altos níveis de radiação solar e a compostos químicos presentes no meio. Essa suscetibilidade limita o uso do organismo bacteriano enquanto agente de controle biológico nos campos de produção agrícola, sendo, preferível, a utilização de produtos gerados pelo metabolismo secundário da bactéria, como as proteínas-Cry (Preston et al., 2003).

A bactéria B. nematocida B16 é um organismo esporogênico, que foi isolado pela primeira vez na China e que apresenta elevada atividade nematicida sobre a espécie Panagrellus redivivus (Huang et al., 2005). Essa bactéria leva o nematoide à morte por um mecanismo conhecido como 'Cavalo de Tróia' (Trojan horse mechanism) (Niu et al., 2010). Nesse processo, a bactéria atrai o verme produzindo compostos orgânicos voláteis, como o benzaldeído e 2-heptanona. Uma vez ingerida pelo nematoide, a bactéria secreta proteases extracelulares, como a serina alcalina Bace16 e a protease neutra Bae16, que atacam os tecidos intestinais do hospedeiro, levando-o à morte. O mecanismo de patogenicidade 'Cavalo de Tróia' da bactéria B. nematocida B16 expande o entendimento científico sobre a diversidade dos mecanismos de patogenicidade utilizados por bactérias do gênero Bacillus (Niu et al., 2010).

\section{Considerações Finais}

As bactérias do gênero Bacillus passaram por várias fases do desenvolvimento científico, desde a sua descoberta. Os avanços tecnológicos mostraram a grande versatilidade dessas bactérias e a possibilidade de uso destas. A capacidade de ocupar diferentes nichos e a ampla diversidade fisiológica desses organismos, colocam as bactérias desse gênero no foco de importantes pesquisas. Adicionalmente, pesquisas que se dediquem à otimização de produtos bioformulados e utilização de produtos do metabolismo secundário de Bacillus são extremamente importantes, pois elas darão suporte para o correto uso desses organismos aplicados em sistemas de manejo integrado de doenças, impedido que essa tecnologia seja subutilizada.

Finalmente, a utilização de bactérias e produtos do metabolismo microbiano desses indivíduos, para fins de controle de doenças em plantas, tem, cada vez mais, espaço dentre pequenos, médios e até grandes produtores que se preocupam com a crescente demanda mundial por alimentos livres de resíduos químicos, e que enxergam nesse panorama, um crescente nicho de mercado que é promissor, crescente e cheio de possibilidades. 


\section{Referências}

Almenar, E., Del Valle, V., Catala, R., \& Gavara, R. (2007). Active package for wild strawberry fruit (Fragaria vesca L.). Journal of Agricultural and Food chemistry, 55(6), 2240-2245.

Alves, E. (2007). Mecanismos estruturais na resistência de plantas a patógenos. Summa Phytopathol, 33, $154-156$.

Araujo, F. D. (2008). Inoculação de sementes com Bacillus subtilis, formulado com farinha de ostras e desenvolvimento de milho, soja e algodão. Ciência e Agrotecnologia, 32(2), 456-462.

Araújo, F. F. D., \& Marchesi, G. V. P. (2009). Uso de Bacillus subtilis no controle da meloidoginose e na promoção do crescimento do tomateiro. Ciência Rural, 39(5), 1558-1561.

Araújo, F. F. D., Silva, J. F. V., \& Araújo, A. S. F. D. (2002). Influência de Bacillus subtilis na eclosão, orientação e infecção de Heterodera glycines em soja. Ciência Rural, 32(2), 197-203.

Azevedo, J. L., Maccheroni Jr, W., Pereira, J. O., \& de Araújo, W. L. (2000). Endophytic microorganisms: a review on insect control and recent advances on tropical plants. Electronic Journal of Biotechnology, 3(1), 15-16.

Bais, H. P., Fall, R., \& Vivanco, J. M. (2004). Biocontrol of Bacillus subtilis against infection of Arabidopsis roots by Pseudomonas syringae is facilitated by biofilm formation and surfactin production. Plant physiology, 134(1), 307-319.

Bettucci, L., \& Alonso, R. (1997). A comparative study of fungal populations in healthy and symptomatic twigs of Eucalyptus grandis in Uruguay. Mycological Research, 101(9), 1060-1064.

Bleich, R., Watrous, J. D., Dorrestein, P. C., Bowers, A. A., \& Shank, E. A. (2015). Thiopeptide antibiotics stimulate biofilm formation in Bacillus subtilis. Proceedings of the National Academy of Sciences, 112(10), 3086-3091.

Bouton, J. H., \& Hopkins, A. A. (2003). Commercial applications of endophytic fungi. Clavicipitalean fungi: evolutionary biology, chemistry, biocontrol and cultural impacts, 495-516.

Cankar, K., Kraigher, H., Ravnikar, M., \& Rupnik, M. (2005). Bacterial endophytes from seeds of Norway spruce (Picea abies L. Karst). FEMS microbiology letters, 244(2), 341-345.

Cavaglieri, L. R., Passone, A., \& Etcheverry, M. G. (2004). Correlation between screening procedures to select root endophytes for biological control of Fusarium verticillioides in Zea mays L. Biological Control, 31(3), 259-267.

Chen, H., Xiao, X., Wang, J., Wu, L., Zheng, Z., \& Yu, Z. (2008). Antagonistic effects of volatiles generated by Bacillus subtilis on spore germination and hyphal growth of the plant pathogen, Botrytis cinerea. Biotechnology letters, 30(5), 919-923.

Choudhary, D. K., Prakash, A., \& Johri, B. N. (2007). Induced systemic resistance (ISR) in plants: mechanism of action. Indian Journal of Microbiology, 47(4), 289-297.

Claus, D.R., Berkeley, C.W. The genus Bacillus. SNEATH, P.H.A. (Eds.). (1986). Bergey's manual of systematic bacteriology. v. 2. Baltimore: Williams and Wilkins.

Coombs, J. T., \& Franco, C. M. (2003). Visualization of an endophytic Streptomyces species in wheat seed. Applied and Environmental Microbiology, 69(7), 4260-4262.

Coombs, J. T., Michelsen, P. P., \& Franco, C. M. (2004). Evaluation of endophytic actinobacteria as antagonists of Gaeumannomyces graminis var. tritici in wheat. Biological control, 29(3), 359-366.

Durham, D. R., Stewart, D. B., \& Stellwag, E. J. (1987). Novel alkaline-and heat-stable serine proteases from alkalophilic Bacillus sp. strain GX6638. Journal of Bacteriology, 169(6), 2762-2768.

Durmaz, E., Hu, Y., Aroian, R. V., \& Klaenhammer, T. R. (2016). Intracellular and extracellular expression of Bacillus thuringiensis crystal protein Cry5B in Lactococcus lactis for use as an anthelminthic. Applied and environmental microbiology, 82(4), 1286-1294.

El-Tarabily, K. A. (2003). An endophytic chitinase-producing isolate of Actinoplanes missouriensis, with potential for biological control of root rot of lupin caused by Plectosporium tabacinum. Australian Journal of Botany, 51(3), 257-266.

Eppinger, M., Bunk, B., Johns, M. A., Edirisinghe, J. N., Kutumbaka, K. K., Koenig, S. S., \& Vary, P. S. (2011). Genome sequences of the biotechnologically important Bacillus megaterium strains QM B1551 and DSM319. Journal of bacteriology, 193(16), 4199-4213.

Estrela, C. (2018). Metodologia científica: ciência, ensino, pesquisa. Artes Médicas.

Fernandes, R. H., Vieira, B. S., Fuga, C. A. G., \& Lopes, E. A. (2014). Pochonia chlamydosporia e Bacillus subtilis no controle de Meloidogyne incognita e M. javanica em mudas de tomateiro. Bioscience Journal, 30(1).

Ferraz, S., \& Valle, L. D. (1997). Controle de fitonematóides por plantas antagônicas. UFV.

Ficth, W. M., \& Margoliash, E. (1967). Construction of phylogenetic trees: a method based on mutation distances as estimated from cytochrome c sequences is of general applicability. Science, 155, 279-284.

Fox, G. E., Pechman, K. R., \& Woese, C. R. (1977). Comparative cataloging of 16S ribosomal ribonucleic acid: molecular approach to procaryotic systematics. International Journal of Systematic and Evolutionary Microbiology, 27(1), 44-57. 
Freitas, L.G., Oliveira, R.D.L., Ferraz, S. (2001). Introdução à nematologia. Universidade Federal de Viçosa.

Germida, J. J., Siciliano, S. D., Renato de Freitas, J., \& Seib, A. M. (1998). Diversity of root-associated bacteria associated with field-grown canola (Brassica napus L.) and wheat (Triticum aestivum L.). FEMS Microbiology Ecology, 26(1), 43-50.

Gordon, R. E. (1981). One hundred and seven years of the genus Bacillus. The Aerobic Endospore Forming Bacteria, 9-45.

Gordon, R. E., Haynes, W. C., \& Pang, C. H. N. (1973). The genus bacillus (No. 427). Agricultural Research Service, US Department of Agriculture.

Griffitts, J. S., Haslam, S. M., Yang, T., Garczynski, S. F., Mulloy, B., Morris, H., \& Aroian, R. V. (2005). Glycolipids as receptors for Bacillus thuringiensis crystal toxin. Science, 307(5711), 922-925.

Guettler, M., \& Hanson, R. S. (1988, May). Characterization of a Methanol Oxidizing Thermophilic Member of the Genus Bacillus. In Poster Session Materials presented at the 88th Annual Meeting of the American Society for Microbiology, Wednesday.

Hallmann, J., Faupel, A., Krechel, A., Sikora, R., \& Berg, G. (2004). Endophytic bacteria and biological control of nematodes. IOBC/WPRS Bulletin, 27, 8395.

Hallmann, J., Quadt-Hallmann, A., Mahaffee, W. F., \& Kloepper, J. W. (1997). Bacterial endophytes in agricultural crops. Canadian journal of microbiology, 43(10), 895-914.

Hammami, I., Rhouma, A., Jaouadi, B., Rebai, A., \& Nesme, X. (2009). Optimization and biochemical characterization of a bacteriocin from a newly isolated Bacillus subtilis strain 14B for biocontrol of Agrobacterium spp. strains. Letters in applied microbiology, 48(2), 253-260.

Handoo, Z.A. (1998). Plant parasitic nematodes. <http://www.ars.usda.gov/ Services/docs/htm〉.

Henning, K., Villforth, F. (1995). Experimentalle untersuchungen zur frage der bacteriensymbiose in Höeheren Pflanzen und Ihre Beeinflussung durch "Leitemente". Biochemische Zeitschrift 350(1), 117-125.

Huang, X. W., Niu, Q. H., Zhou, W., \& Zhang, K. Q. (2005). Bacillus nematocida sp. nov., a novel bacterial strain with nematotoxic activity isolated from soil in Yunnan, China. Systematic and applied microbiology, 28(4), 323-327.

Hunger, W., \& Claus, D. (1981). Taxonomic studies on Bacillus megaterium and on agarolytic Bacillus strains. The aerobic endospore-forming bacteria: classification and identification, 217-239.

Iatsenko, I., Corton, C., Pickard, D. J., Dougan, G., \& Sommer, R. J. (2014). Draft genome sequence of highly nematicidal Bacillus thuringiensis DB27. Genome announcements, 2(1).

Ivanova, N., Sorokin, A., Anderson, I., Galleron, N., Candelon, B., Kapatral, V., \& Kyrpides, N. (2003). Genome sequence of Bacillus cereus and comparative analysis with Bacillus anthracis. Nature, 423(6935), 87-91.

De Vrind, J. P., Boogerd, F. C., \& de Vrind-de Jong, E. W. (1986). Manganese reduction by a marine Bacillus species. Journal of bacteriology, 167(1), 30-34.

Kado, C.I. (1992). Plant pathogenic bacteria. In: Balows, A., Trüper, H.G., Dworkin, M., Harder, W., Schleifer, K.H. (Ed.). The prokaryotes. Springer-Verlag, $660-662$.

Kai, M., Effmert, U., Berg, G., \& Piechulla, B. (2007). Volatiles of bacterial antagonists inhibit mycelial growth of the plant pathogen Rhizoctonia solani. Archives of microbiology, 187(5), 351-360.

Keynan, A., \& Sandler, N. (1983). Spore research in historical perspective.

Kiraly, Z., \& Hornok, L. (1997). Molecular aspects of plant-pathogen interactions in relation to novel strategies of breeding for disease resistance. Acta phytopathologica et entomologica hungarica, 32(1-2), 1-28.

Kitada, M. A. K. I. O., \& Horikoshi, K. O. K. I. (1987). Bioenergetic properties of alkalophilic Bacillus sp. strain C-59 on an alkaline medium containing K2CO3. Journal of bacteriology, 169(12), 5761-5765.

Kitada, M. A. K. I. O., Onda, K. E. N. S. U. K. E., \& Horikoshi, K. O. K. I. (1989). The sodium/proton antiport system in a newly isolated alkalophilic Bacillus sp. Journal of bacteriology, 171(4), 1879-1884.

Kunst, F., Debarbouille, M., Msadek, T., Young, M., Mauel, C., Karamata, D., \& Dedonder, R. (1988). Deduced polypeptides encoded by the Bacillus subtilis sacU locus share homology with two-component sensor-regulator systems. Journal of bacteriology, 170(11), 5093-5101.

Koch, D., Mirza, Z., Hu, Y. (2016). Crystal protein Cry5B as a novel and powerful anthelmintic. Massachusetts: Center for Clinical and Translational Science. <http://escholarship.umassmed.edu/cgi/viewcontent.cgi?article=1397\&context=cts_retreat〉.

Kunkel, B. A., \& Grewal, P. S. (2003). Endophyte infection in perennial ryegrass reduces the susceptibility of black cutworm to an entomopathogenic nematode. Entomologia Experimentalis et Applicata, 107(2), 95-104.

Kupper, K. C., Gimenes-Fernandes, N., \& Goes, A. D. (2003). Controle biológico de Colletotrichum acutatum, agente causal da queda prematura dos frutos cítricos. Fitopatologia brasileira, 28(3), 251-257.

Lanna Filho, R., Ferro, H. M., \& de Pinho, R. S. C. (2010). Controle biológico mediado por Bacillus subtilis. Revista Trópica: Ciências Agrárias e Biológicas, 4(2). 
Leelasuphakul, W., Hemmanee, P., \& Chuenchitt, S. (2008). Growth inhibitory properties of Bacillus subtilis strains and their metabolites against the green mold pathogen (Penicillium digitatum Sacc.) of citrus fruit. Postharvest Biology and Technology, 48(1), 113-121.

Li, J., Zou, C., Xu, J., Ji, X., Niu, X., Yang, J., \& Zhang, K. Q. (2015). Molecular mechanisms of nematode-nematophagous microbe interactions: basis for biological control of plant-parasitic nematodes. Annual review of phytopathology, 53, 67-95.

Li, X. Q., Wei, J. Z., Tan, A., \& Aroian, R. V. (2007). Resistance to root-knot nematode in tomato roots expressing a nematicidal Bacillus thuringiensis crystal protein. Plant biotechnology journal, 5(4), 455-464.

Ludwig, J., Moura, A. B., \& Gomes, C. B. (2013). Potencial da microbiolização de sementes de arroz com rizobactérias para o biocontrole do nematoide das galhas. Tropical Plant Pathology, 38(3), 264-268.

Luo, H., Xiong, J., Zhou, Q., Xia, L., \& Yu, Z. (2013). The effects of Bacillus thuringiensis Cry6A on the survival, growth, reproduction, locomotion, and behavioral response of Caenorhabditis elegans. Applied microbiology and biotechnology, 97(23), 10135-10142.

Maciel, S. L., \& Ferraz, L. C. C. B. (1996). Reprodução de Meloidogyne incognita raça 2 e de Meloidogyne javanica em oito espécies de plantas medicinais. Scientia Agricola, 53(2-3), 232-236.

Maget-Dana, R., Thimon, L., Peypoux, F., \& Ptak, M. (1992). Surfactin/iturin A interactions may explain the synergistic effect of surfactin on the biological properties of iturin A. Biochimie, 74(12), 1047-1051.

Manjula, K., \& Podile, A. R. (2005). Increase in seedling emergence and dry weight of pigeon pea in the field with chitin-supplemented formulations of Bacillus subtilis AF 1. World Journal of Microbiology and Biotechnology, 21(6), 1057-1062.

Mcafee, B.J., Taylor, A. (2001). Some aspects of the ecology and physiology off ungi isolated predominently from the wood of trees of the northern temperate forest. Proceedings of the Nova Scotian Institute of Science, 41(1), 160-213.

McInroy, J. A., \& Kloepper, J. W. (1995). Survey of indigenous bacterial endophytes from cotton and sweet corn. Plant and soil, 173(2), 337-342.

McNeill, M. R., Proffitt, J. R., Barlow, N. D., \& Goldson, S. L. (2003). Population regulation of Argentine stem weevil Listronotus bonariensis (Kuschel)(Coleoptera: Curculionidae) in dryland New Zealand pastures: a multitrophic interaction. Environmental entomology, 32(4), 771-779.

Monteiro, A. R. (1970). Dorylaimoidea de cafezais paulistas (Nemata, Dorylaimida). Escola Superior de Agricultura Luiz de Queiroz, Piracicaba, SP (Brasil).

Musson, G. (1994). Ecology and effects of endophytic bacteria in plants (Doctoral dissertation, Auburn University).

Nakamura, L. K. (1987). Bacillus alginolyticus sp. nov. and Bacillus chondroitinus sp. nov., two alginate-degrading species. International Journal of Systematic and Evolutionary Microbiology, 37(3), 284-286.

Nakamura, L.K. (1984). Bacillus pulvifasciens sp. nov., nom. rev. International Journal of Systematic Bacteriology 34(1), 410-413.

Nakamura, L. K., Blumenstock, I., \& Claus, D. (1988). Taxonomic Study of Bacillus coagulans Hammer 1915 with a Proposal for Bacillus smithii sp. nov. International Journal of Systematic and Evolutionary Microbiology, 38(1), 63-73.

Ngugi, H. K., Dedej, S., Delaplane, K. S., Savelle, A. T., \& Scherm, H. (2005). Effect of flower-applied Serenade biofungicide (Bacillus subtilis) on pollination-related variables in rabbiteye blueberry. Biological Control, 33(1), 32-38.

Niu, Q., Huang, X., Zhang, L., Xu, J., Yang, D., Wei, K., \& Zhang, K. Q. (2010). A Trojan horse mechanism of bacterial pathogenesis against nematodes. Proceedings of the National Academy of Sciences, 107(38), 16631-16636.

Norris, J. R., Berkeley, R. C. W., Logan, N. A., \& O'donnell, A. G. (1981). The genera Bacillus and Sporolactobacillus. The prokaryotes, 2, 1711-1742.

Nunes, H. T., Monteiro, A. C., \& Pomela, A. W. V. (2010). Uso de agentes microbianos e químico para o controle de Meloidogyne incognita em soja. Acta Scientiarum. Agronomy, 32(3), 403-409.

Ongena, M., Duby, F., Jourdan, E., Beaudry, T., Jadin, V., Dommes, J., \& Thonart, P. (2005). Bacillus subtilis M4 decreases plant susceptibility towards fungal pathogens by increasing host resistance associated with differential gene expression. Applied Microbiology and Biotechnology, 67(5), 692-698.

Ongena, M., Jourdan, E., Adam, A., Paquot, M., Brans, A., Joris, B., \& Thonart, P. (2007). Surfactin and fengycin lipopeptides of Bacillus subtilis as elicitors of induced systemic resistance in plants. Environmental microbiology, 9(4), 1084-1090.

Pal, K. K., \& Gardener, B. M. (2006). Biological control of plant pathogens. The plant health instructor, 2, 1117-1142.

Pascholati, S.F. (2011). Fisiologia do parasitismo: como os patógenos atacam as plantas. In: Amorin, L., Rezende, J.A.M., Bergamin Filho, A. Manual de Fitopatologia: princípios e conceitos 1(1), 545-591.

Pascholati, S. F., Melo, T. D., \& Dalio, R. J. D. (2015). Indução de resistência contra patógenos: definição e perspectivas de uso. Visão agrícola nº 13 jul, 110 112.

Patiño-Navarrete, R., Sanchis, V. (2016). Evolutionary processes and environmental factors underlying the genetic diversity and lifestyles of Bacillus cereus group bacteria. Research in Microbiology. <http://www.sciencedirect.com/science/article/pii/S092325081 6300754>.

Perchat, S., Dubois, T., Zouhir, S., Gominet, M., Poncet, S., Lemy, C., \& Lereclus, D. (2011). A cell-cell communication system regulates protease production during sporulation in bacteria of the Bacillus cereus group. Molecular microbiology, 82(3), 619-633.

Persello-Cartieaux, F., Nussaume, L., \& Robaglia, C. (2003). Tales from the underground: molecular plant-rhizobacteria interactions. Plant, Cell \& Environment, 26(2), 189-199. 
Pettit, R. E., Taber, R. A., \& Foster, B. G. (1968). Occurrence of Bacillus subtilis in peanut kernels. Phytopathology, 58(2), 254-255.

Pichinoty, F., Asselineau, J., \& Mandel, M. (1984, September). Caractérisation biochimique de Bacillus benzoevorans sp. nov., une nouvelle espèce filamenteuse, engainée et mésophile, dégradant divers acides aromatiques et phénols. In Annales de l'Institut Pasteur/Microbiologie. 135, 209-217. Elsevier Masson.

Pichinoty, F., Waterbury, J. B., Mandel, M., \& Asselineau, J. (1986, January). Bacillus gordonae sp. nov., une nouvelle espece appartenant au second groupe morphologique, dégradant divers composés aromatiques. In Annales de l'Institut Pasteur/Microbiologie. 137, 65-78. Elsevier Masson.

Pieterse, C. M., \& Van Loon, L. C. (2004). NPR1: the spider in the web of induced resistance signaling pathways. Current opinion in plant biology, 7(4), 456464.

Prasad, S. S. S. V., Tilak, K. V. B. R., \& Gollakota, K. G. (1972). Role of Bacillus thuringiensis var. thuringiensis on the larval survivability and egg hatching of Meloidogyne spp., the causative agent of root knot disease. J Invertebrate Pathol.

Preston, J. F., Dickson, D. W., Maruniak, J. E., Nong, G., Brito, J. A., Schmidt, L. M., \& Giblin-Davis, R. M. (2003). Pasteuria spp.: systematics and phylogeny of these bacterial parasites of phytopathogenic nematodes. Journal of Nematology, 35(2), 198.

Raaijmakers, J. M., De Bruijn, I., Nybroe, O., \& Ongena, M. (2010). Natural functions of lipopeptides from Bacillus and Pseudomonas: more than surfactants and antibiotics. FEMS microbiology reviews, 34(6), 1037-1062.

Ravichandra, N.G. (2014). Phytonematodes: treat to horticulture. Horticultural Nematology 2(1), 5-16.

Redlin, S.C., Carris, L. M. (1996). Endophytic fungi in grasses and woody plants: systematics, ecology and evolution. APS Press, 231.

Riggs, P. J., Chelius, M. K., Iniguez, A. L., Kaeppler, S. M., \& Triplett, E. W. (2001). Enhanced maize productivity by inoculation with diazotrophic bacteria. Functional Plant Biology, 28(9), 829-836.

Romeiro, R. D. S. (2007). Controle biológico de doenças de plantas: fundamentos. Universidade Federal de Viçosa.

Rosson, R. A., \& Nealson, K. H. (1982). Manganese binding and oxidation by spores of a marine bacillus. Journal of Bacteriology, 151(2), $1027-1034$.

Ryu, C. M., Farag, M. A., Hu, C. H., Reddy, M. S., Kloepper, J. W., \& Paré, P. W. (2004). Bacterial volatiles induce systemic resistance in Arabidopsis. Plant physiology, 134(3), 1017-1026.

Saitou, N., \& Nei, M. (1987). The neighbor-joining method: a new method for reconstructing phylogenetic trees. Molecular biology and evolution, 4(4), 406425 .

Sanahuja, G., Banakar, R., Twyman, R. M., Capell, T., \& Christou, P. (2011). Bacillus thuringiensis: a century of research, development and commercial applications. Plant biotechnology journal, 9(3), 283-300.

Schendel, F. J., Bremmon, M. G., Flickinger, M. G., \& RS, H. (1989). L-Lysine production from methanol at high cell densities of MGA3, a thermophilic Bacillus. In Abstract from 1989 ASM Annual Meeting (published Mar. 21, 1989).

Schulthess, F. M., \& Faeth, S. H. (1998). Distribution, abundances, and associations of the endophytic fungal community of Arizona fescue (Festuca arizonica). Mycologia, 90(4), 569-578.

Scott, B., \& Young, C. (2003). Genetic manipulation of clavicipitalean endophytes. In: biocontrole and cultural impacts. New York USA: Marcel Dekker Inc., 425-443.

Sikora, R. A. (1992). Management of the antagonistic potential in agricultural ecosystems for the biological control of plant parasitic nematodes. Annual review of phytopathology, 30, 245-270.

Padgham, J. L., \& Sikora, R. A. (2007). Biological control potential and modes of action of Bacillus megaterium against Meloidogyne graminicola on rice. Crop protection, 26(7), 971-977.

Slepecky, R. A. (1972). Ecology of bacterial sporeformers. In: Halvorson, H.G., Hanson, R., Campbell, L.L. (Ed.). Spores V. Washington, DC: American Society of Microbiology, 297-313.

Slepecky, R. A., \& Hemphill, H. E. (2006). The genus Bacillus - nonmedical. In: Dworkin, M., Falkov, S., Rosenberg, E., Schileifer, K-H., Stackebrandt, E. (Ed.). The prokaryotes. A handbook on the biology of bacteria. Bacteria: Frimicutes, Cyanobacteria. 3rd. Ed. v.4. Minneapolis: Springer.

Slepecky, R. A., \& Leadbetter, E. R. (1984). On the prevalence and roles of sporeforming bacteria and their spores in nature. Hurst, A., Gould, G.W. (Ed.). The bacterial spore. Academic Press, 79-99.

Slepecky, R. A., \& Leadbetter, E. R. (1977). The diversity of spore-forming bacteria: some ecological implications. In: Barker, A.N., Wolf, J., Ellar, D.J., Dring, G.J., Gould, G.W. (Ed.). Spore Research. London: Academic Press, 869-877.

Smith, H., Wingfield, M. J., \& Petrini, O. (1996). Botryosphaeria dothidea endophytic in Eucalyptus grandis and Eucalyptus nitens in South Africa. Forest ecology and management, 89(1-3), 189-195.

Smith, N. R., Gordon, R. E., \& Clark, F. E. (1946). Aerobic mesophilic sporeforming bacteria (Vol. 552). US Department of Agriculture.

Smith, N. R., Gordon, R. E., \& Clark, F. E. (1952). Aerobic sporeforming bacteria (No. 16). US Government Printing Office.

Sneath, P. H. A., \& Sokal, R.R. (1973). Numerical taxonomy.: W.H. Freeman. 
Stackebrandt, E., Ludwig, W., Weizenegger, M., Dorn, S., McGill, T. J., Fox, G. E., \& Schleifer, K. H. (1987). Comparative 16S rRNA oligonucleotide analyses and murein types of round-spore-forming bacilli and non-spore-forming relatives. Microbiology, 133(9), 2523-2529.

Stackebrandt, E., \& Woese, C. R. (1979). A phylogenetic dissection of the family Micrococcaceae. Current Microbiology, 2(6), 317-322.

Stackebrandt, E., Woese, C. R. (1981).The evolution of prokaryotes. In: Carlile, M.J., Collings, J.F., Moseley, B.E.B. (Ed.). Molecular and cellular aspects of microbial evolution. Cambridge: Cambridge University Press, 1-31.

Stein, T. (2005). Bacillus subtilis antibiotics: structures, syntheses and specific functions. Molecular microbiology, 56(4), 845-857.

Stirling, G. R., Nicol, J. M., \& Reay, F. (1998). Advisory services for nematodes pests-operational guide (Rural Industries Research and Development Corporation Publication No. 99/41, 120 pp.). Whitehead, AG Plant nematode control. Wallingford: CAB.

Sturz, A.V., Kimpinski, J. (2003). Endoroot bacteria derived from marigolds (Tagetes spp.) can decrease soil population densities of root-lesion activity. World Journal of Microbiology and Biotechnology 19 (1), 381-385.

Trevet, I. W. (1948). Bacteria in the storage organs of healthy plants. Phytopathology, 38, 960-967.

Tsavkelova, E. A., Klimova, S. Y., Cherdyntseva, T. A., \& Netrusov, A. I. (2006). Microbial producers of plant growth stimulators and their practical use: a review. Applied biochemistry and microbiology, 42(2), 117-126.

Tuzun, S. (2001). The relationship between pathogen-induced systemic resistance (ISR) and multigenic (horizontal) resistance in plants. European Journal of Plant Pathology, 107(1), 85-93.

US Congress Office of Technology Assessment (1995). Biologically-based technologies for pest control. OTA-ENV-636. Washington, DC: US Government Printing Office.

Vachon, V., Laprade, R., \& Schwartz, J. L. (2012). Current models of the mode of action of Bacillus thuringiensis insecticidal crystal proteins: a critical review. Journal of invertebrate pathology, $111(1), 1-12$.

Vaz, M. V., Canedo, E. J., Machado, J. C., Vieira, B. S., \& Lopes, E. A. (2011). Controle biológico de Meloidogyne javanica e Meloidogyne incognita com Bacillus subtilis. Perquirere, 8, 203-212.

Voss, G. B. (2013). Produção de Bacillus subtilis em biorreator airlift e sua aplicação no controle de nematoide de galhas do tomateiro.

Wang, J., Liu, J., Wang, X., Yao, J., \& Yu, Z. (2004). Application of electrospray ionization mass spectrometry in rapid typing of fengycin homologues produced by Bacillus subtilis. Letters in applied microbiology, 39(1), 98-102.

Wei, J. Z., Hale, K., Carta, L., Platzer, E., Wong, C., Fang, S. C., \& Aroian, R. V. (2003). Bacillus thuringiensis crystal proteins that target nematodes. Proceedings of the National Academy of Sciences, 100(5), 2760-2765.

Wu, C. C., Hu, Y., Miller, M., Aroian, R. V., \& Sailor, M. J. (2015). Protection and delivery of anthelmintic protein Cry5B to nematodes using mesoporous silicon particles. ACS nano, 9(6), 6158-6167.

Xiong, J., Zhou, Q., Luo, H., Xia, L., Li, L., Sun, M., \& Yu, Z. (2015). Systemic nematicidal activity and biocontrol efficacy of Bacillus firmus against the root-knot nematode Meloidogyne incognita. World Journal of Microbiology and Biotechnology, 31(4), 661-667.

Yanni, Y. G., Rizk, R. Y., Abd El-Fattah, F. K., Squartini, A., Corich, V., Giacomini, A., \& Dazzo, F. B. (2001). The beneficial plant growth-promoting association of Rhizobium leguminosarum bv. trifolii with rice roots. Functional Plant Biology, 28(9), 845-870.

Yao, A., Bochow, H., Karimov, S., Boturov, U., Sanginboy, S., Sharipov, A. (2006). Effect of FZB 24 Bacillus subtilis as a biofertilizer on cotton yields in field tests. Archives of Phytopathology and Plant Protection, 39(1), 323-328.

Yu, Z., Luo, H., Xiong, J., Zhou, Q., Xia, L., Sun, M., \& Yu, Z. (2014). B acillus thuringiensis C ry6 A exhibits nematicidal activity to C aenorhabditis elegans bre mutants and synergistic activity with C ry5 B to C. elegans. Letters in applied microbiology, 58(6), 511-519.

Zarilla, K. A., \& Perry, J. J. (1987). Bacillus thermokovorans, sp. nov., a species of obligately thermophilic hydrocarbon utilizing endospore-forming bacteria. Systematic and applied Microbiology, 9(3), 258-264.

Zinniel, D. K., Lambrecht, P., Harris, N. B., Feng, Z., Kuczmarski, D., Higley, P., \& Vidaver, A. K. (2002). Isolation and characterization of endophytic colonizing bacteria from agronomic crops and prairie plants. Applied and environmental microbiology, 68(5), 2198-2208. 